\title{
Assessing inconsistency in global land cover products and a synthesis of studies on land use and land cover dynamics during 2001-2017 in the southeastern region of Bangladesh
}

Article

Accepted Version

Islam, S., Zhang, M., Yang, H. and Ma, M. (2019) Assessing inconsistency in global land cover products and a synthesis of studies on land use and land cover dynamics during 2001 2017 in the southeastern region of Bangladesh. Journal of Applied Remote Sensing, 13 (4). 048501. ISSN 1931-3195 doi: https://doi.org/10.1117/1.JRS.13.048501 Available at https://centaur.reading.ac.uk/87109/

It is advisable to refer to the publisher's version if you intend to cite from the work. See Guidance on citing.

To link to this article DOI: http://dx.doi.org/10.1117/1.JRS.13.048501

Publisher: Society of Photo-optical Instrumentation Engineers (SPIE)

All outputs in CentAUR are protected by Intellectual Property Rights law, including copyright law. Copyright and IPR is retained by the creators or other copyright holders. Terms and conditions for use of this material are defined in the End User Agreement. 


\section{www.reading.ac.uk/centaur}

\section{CentAUR}

Central Archive at the University of Reading

Reading's research outputs online 


\section{Assessing inconsistency in global land cover products and a}

2 synthesis of studies on land use and land cover dynamics during

3 2001-2017 in the southeastern region of Bangladesh

Shahidul Islam, ${ }^{\text {a,b,c }}$ Miao Zhang, ${ }^{\mathrm{d}}$ Hong Yang,,${ }^{\mathrm{a}, \mathrm{e}, *}$, Mingguo Ma ${ }^{\mathrm{a}, \mathrm{b}, \mathrm{c}, *}$

${ }^{a}$ Chongqing Jinfo Mountain Field Scientific Observation and Research Station for Kaster Ecosystem, School of Geographical Sciences, Southwest University, Chongqing 400715, China;

${ }^{b}$ Research Base of Karst Eco-environments at Nanchuan in Chongqing, Ministry of Nature Resources, School of Geographical Sciences, Southwest University, Chongqing 400715, China;

${ }^{\mathrm{c} C h o n g q i n g}$ Engineering Research Center for Remote Sensing Big Data Application, School of Geographical

11 Sciences, Southwest University, Chongqing 400715, China;

${ }^{\mathrm{d}}$ Northwest Land and Resources Research Center, Shaanxi Normal University, No. 620, West Chang'an Avenue, Chang'an District, Xi'an 710119, China.

'Department of Geography and Environmental Science, University of Reading, Whiteknights Reading, RG6 6AB, UK.

Abstract. The high-quality Land Use and Land Cover data is important for monitoring and analyzing environmental changes in the background of global warming. This study accessed the spatial and areal inconsistencies in the four most recent multi-resources land cover products in a complex manner using the common classification systems of IGBP-17, IGBP-9, IPCC-5 and TC (vegetation, wetlands and others only). Based on inconsistencies and multi temporal land cover datasets, a synthesis of study was triggered out on land use and land cover dynamics during 20012017 in the southeastern region of Bangladesh. The overall areal and spatial inconsistencies decreased from high to low levels of aggregation (IGBP-17 to TC), indicating that the inconsistencies are not only influenced by the level of thematic detail and landscape complexity but also related to the conversion uncertainties. Overall areal inconsistency in the comparison of the FROM-GLC and GlobeLand30 datasets was the smallest among the six pairs, while, the pair of MODISLC and LULC was observed the highest inconsistencies. Based on overall lower inconsistencies classification system (IGBP-9), the synthetic land use cover changes at the study area were assessed. During the period of study, the areal distribution of forest cover, built-up areas and water were found increased in annually by $0.4 \%$, $1.32 \%$, and $0.3 \%$ respectively, while the croplands and wetlands were respectively decreased by $0.5 \%$ and $0.3 \%$. The dynamic changes of croplands, forest, and artificial surface were identified the prime cyclic land cover change. This research is helpful in providing training areas for the producer of land cover products.

31 Keywords: Areal and spatial inconsistency, multi-resource land cover products, common classification systems, 32 land use and land cover change, Landsat.

33 *Corresponding Author: Hong Yang, E-mail: hongyanghy@gmail.com; Mingguo Ma, Email: mmg@swu.edu.cn 


\section{Introduction}

36 Land use and land cover products are essential input datasets in land surface modeling or climate

37 modeling [1-3] as of distinct land cover types and land cover datasets provides reliable information

38 on carbon, water, and nitrogen processes for further ecology, climate, and hydrology studies [4-

39 9]. With the advent of high-resolution imagery and more robust techniques, moderate-resolution

40 remote sensing data sources have emerged in recent years, and the scientific community has

41 witnessed a significant increase in the availability of land cover maps. Land cover products include

42 the International Geosphere-Biosphere Program (IGBP) DIScover (IGBP-DIS) [10], the

43 University of Maryland(UMD) Land Cover [11], the Global Land Cover (GLC) mapping project

44 (GlobeLand30) [12], the Ecosystem Classification and Land Surface Parameters Database

45 (ECOCLIMAP) [13], the Moderate Resolution Imaging Spectroradiometer (MODIS) Land Cover

46 Product (MODISLC) [14], and the newest Finer Resolution Observation and Monitoring of Global

47 Land Cover (FROM-GLC) [15]. The IGBP-DIS and UMD datasets belong to the first generation

48 of $1 \mathrm{~km}$ global land cover maps, and are derived from 1981 to 1993 Advanced Very High

49 Resolution Radiometer (AVHRR) data using the IGBP (17 land use types in total) and simplified

50 IGBP (14 land use types in total) classification schemes, respectively [11]. The ECOCLIMAP

51 classification scheme comes from the combination of the IGBP-DIS and UMD land cover types

52 and has a spatial scale of $1 \mathrm{~km}$ [16]. MODIS provides global land cover with a spatial resolution

53 of $500 \mathrm{~m}$ using six types of classification schemes [17]. Given the free availability of Landsat and

54 similar resolution satellite data, a few $30 \mathrm{~m}$ GLC datasets had been developed and released in the

55 past few years, including a decadal-scale wall-to-wall GLC data product (GlobeLand30) that

56 shows change in ten land cover types and ten years [18]. These $30 \mathrm{~m}$ GLC datasets provide more

57 details of land cover patterns, permit the detection of land cover change at the scale of most human 
58 land activities, and enable a better understanding of landscape heterogeneity, as well as increase

59 the performance of modeling and simulations [19-20]. The open source FROM-GLC dataset is the

60 first $30 \mathrm{~m}$ global land cover using Landsat data, developed with unique classification scheme based

61 on land cover types from the Food and Agriculture Organization (FAO) of the United Nations and

62 IGBP [15]. Despite the diversity of land cover products available, both data producers and users

63 are frustrated with lack of adequate comparison between such products. Because these land cover

64 products use different classification schemes and spatial resolutions and there is difficulty in

65 selecting and comparing these products for a given application as land use and land cover (LULC)

66 analysis. A specific way to compare datasets is to perform a relative comparison of various land

67 cover maps, first reconciling their thematic classification systems into more aggregated categories

68 after resampling the datasets to be into the same spatial resolution [21].

69 Using common classification systems based on the definition of each class in the original land 70 cover products [22-23] or standards in reference to FAO [24], IGBP [11], or other dataset, some

71 previous studies have highlighted general patterns of agreement, inconsistencies and accuracy

72 among different land cover products at global [25-26], continental [24], national [22], and

73 provincial scales [27]. Other studies not only demonstrated the compatibility and discrepancies

74 between different datasets, but also qualitatively discussed the impacts of landscape in

75 homogeneity, thematic resolution, spatial resolution, and mis-registration errors on product

76 accuracy $[26,28]$. However, few studies have focused on quantitatively examining the

77 uncertainties of classification system conversion, and examined the inconsistencies in the complex

78 land surface areas or approached the subject from the perspective of the complex landscape 79 features. 
Rapidly increasing population growth has resulted in high rates of deforestation and large tracts

81 of forests transitioning into cultivated land; this transition has been recognized as a dominant land

82 cover worldwide [29]. Asia has undergone the most rapid land cover changes in recent years;

83 which has resulted in rapidly increasing cropland and large-scale deforestation in south Asian

84 countries [30]. The area of per capita arable land in the south Asia is very low as compared to other

85 continents. According to FAO (2014) [31], after the Maldives in south Asia, the 0.06 ha/person

86 for Bangladesh is the lowest per capita land ratio worldwide. Clearly, the per capita agricultural

87 land is decreasing as total population continues to increase. Among south Asian countries,

88 Bangladesh potentially has the most serious conditions per capita agriculture land, with the rate

89 decreasing $0.11,0.09,0.07$, and $0.06 \mathrm{ha} /$ person in $1981,1991,2001$, and 2011 respectively [31-

90 32]. In addition, due to the high population growth, per capita arable land was about 2122

91 person $/ \mathrm{km}^{2}$ in 2016 [33], which is the least area per person within the Asian countries outside of

92 the Maldives. Therefore, it also called the land-hungry country [34]. Southeastern region of

93 Bangladesh is a densely populated region with a complex landscapes basin of alluvial floodplain,

94 tidal and coastal floodplain, terrace land, and hills where vegetation and trees outside of forests

95 play an important role in the national economy and carbon sequestration [35]. The primary LULC

96 classes in here are agricultural land, urban and built-up area, forest and vegetation, water bodies,

97 and wetlands [36]. The natural vegetation of this region consists of tropical moist deciduous and

98 semi-evergreen forests, mangroves, and fresh water wetlands [37]. The eastern forests belts of the

99 study area, at the border with Myanmar, are related to the Indo-Burma biodiversity hotspot, one of

100 the few globally significant areas with high species diversity and endemism [38].

101 Scientifically and systematically documenting land cover and land use changes over past

102 several decades is important for understanding the consequences of these changes for human 
103 welfare [30]. Therefore, the objective of this paper is to assess the areal and spatial inconsistencies

104 in different global land cover products and their synthesis analysis of land use and land cover

105 dynamics. The four most recent global land cover products as the MODISLC, GlobeLand30,

106 FROM-GLC, and LULC class of the Landsat satellite imagery data were compared with each

107 other. Each of them used different classification schemes, supporting the present investigation. To

108 assess the effects of diverse thematic details on the uncertainties and discrepancies in the datasets,

109 we selected a 17-class IGBP classification system (IGBP-17), a 9-class IGBP classification system

110 (IGBP-9), a 5-class IPCC classification system (IPCC-5) and finally at the highest level of 111 aggregation, vegetation, wetlands and others only (TC) as common classification systems. The

112 detailed research steps include the quantitatively analyzing the uncertainty caused by classification

113 system conversion and pair wise each class and overall areal inconsistencies of the four land cover

114 products in based on the uncertainties. Based on inconsistencies and above four different land

115 cover products, a synthetic dynamics of land use and land cover changes at different spatial and

116 temporal scale was also analyzed covering the study area from 2001 to 2017.

\section{Materials and Methods}

$118 \quad 2.1$ Study Area

119 This study incorporated data for the southeastern region of Bangladesh, between the latitudes $12022^{\circ} 40^{\prime}-24^{\circ} 10^{\prime} \mathrm{N}$ and longitude $90^{\circ} 45^{\prime}-92^{\circ} 40^{\prime} \mathrm{E}$ with an area of 33,904 sq. km [39-40]. It shares

121 land borders with Bay of Bengal in the south, India and Myanmar in the east and the locally largest

122 river as well the Meghna River (based on water discharged) is in the north and west borders of the 123 study area (Fig. 1). Geographically, it is the largest administrative division of Bangladesh out of 124 eight [39-40] and a population of 29.15 million in consisting density of 884 persons per sq. $\mathrm{km}$ 
125 [41]. The northern and western portions are listed as low-lying alluvial floodplains of the Meghna 126 River that are less than $10 \mathrm{~m}$ above sea level, comprising $37.6 \%$ of the region. However, the 127 remaining southern and eastern portion, where the elevation exceeds $200 \mathrm{~m}$, comprises $62.4 \%$ of 128 the area, mostly with a south-north distributed hilly nature [41]. The eastern portion hilly regions 129 are mostly covered by dense forest with a variety wild life. The mega-river basin has played a 130 crucial role in supporting agriculture, groundwater recharge, fish farming, and land building 131 activities throughout history [42]. The vast areas of plain lands are mainly alluvial river

132 floodplains, estuarine floodplains, wetlands, tidal floodplains, coastal plains, and a small portion 133 of terraced land in nature. 


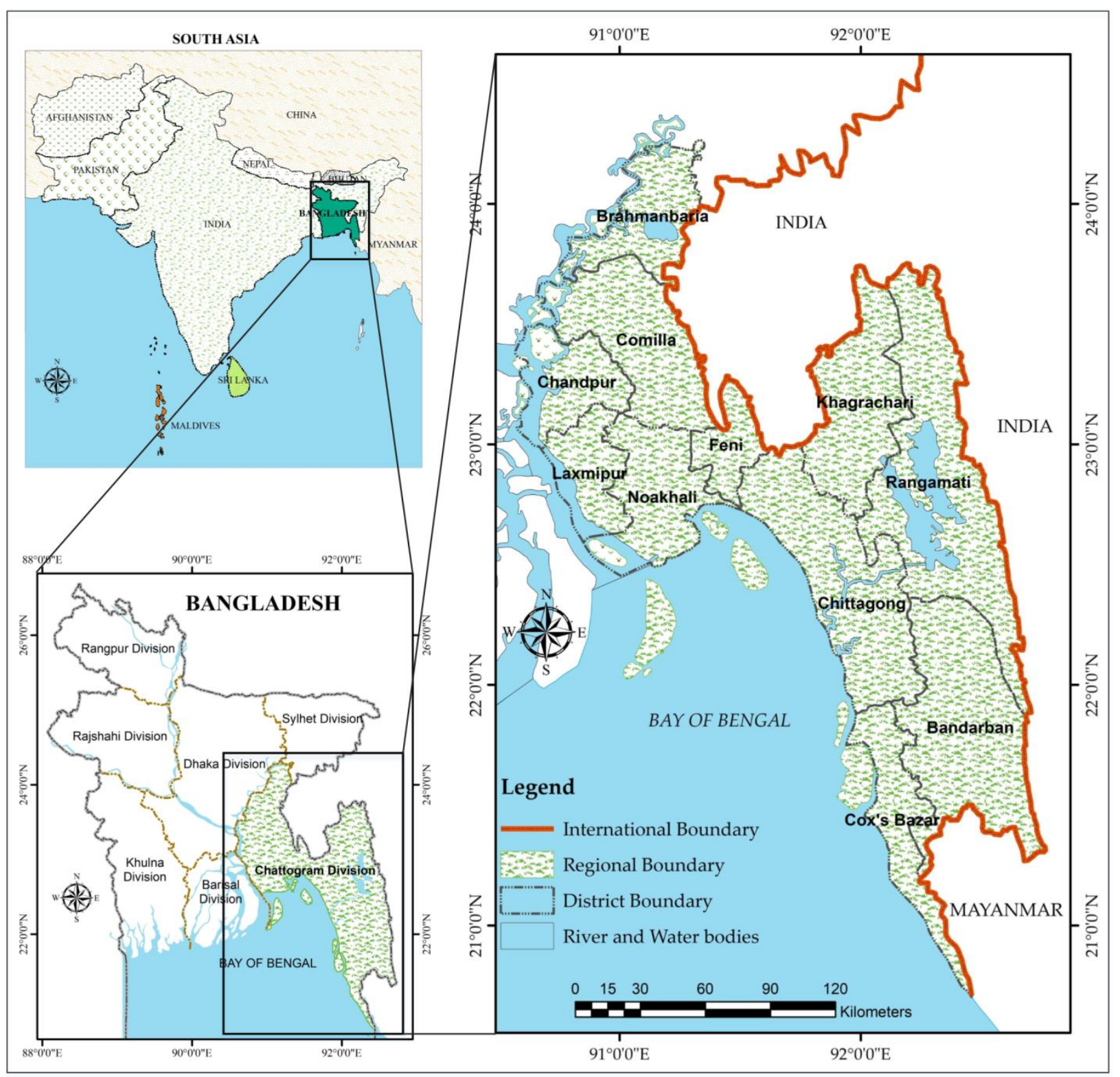

Fig. 1 Location of the study area the Southeastern region of Bangladesh

\subsection{Datasets}

137 To monitor and quantify the inconsistencies in global land cover products and heterogeneous

138 landscapes and land cover change dynamics in the southeastern region of Bangladesh, high

139 temporal and multiresolution recent global land cover products and remote sensing satellite

140 imaginaries were used as datasets to be evaluated in this study. Three recent land cover products 
141 were the MODISLC, GlobeLand30, and FROM-GLC land cover datasets and LULC class images

142 were collected from Landsat Thematic Mapper (TM) and Landsat Enhanced Thematic Mapper

143 Plus (ETM+). These products are derived from newer satellite images and are validated or assessed

144 by the producers on worldwide scales in reference to Google Earth, Virtual Earth, Yahoo maps,

145 and others. The usefulness of these four datasets to different regional investigators has rarely been

146 reported. Fig. 2 has described the datasets products, processing and analysis in a flowchart.

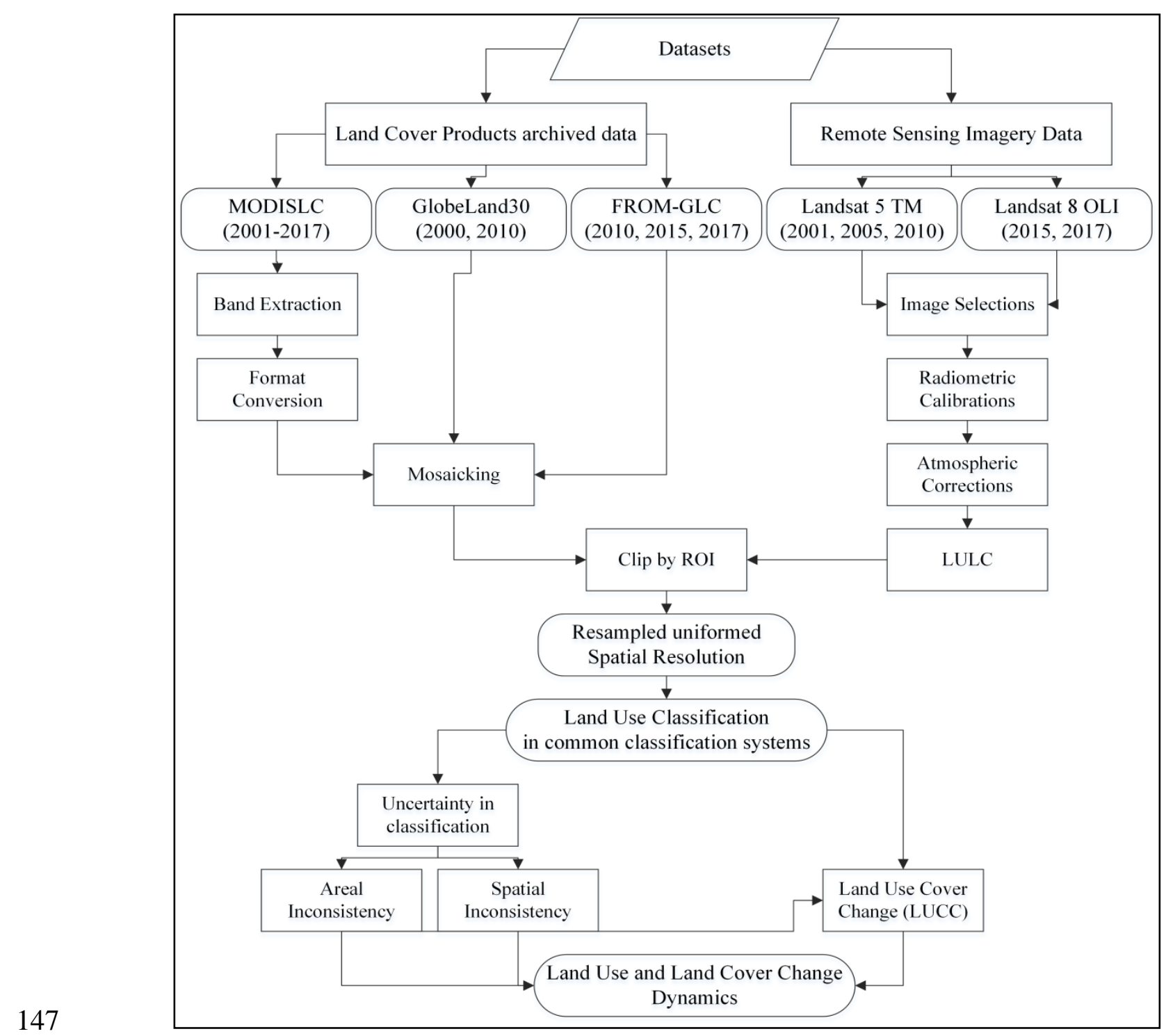

148 Fig. 2 Data analysis flowchart. ROI: Region of Interest; LULC: Land Use and Land Cover; LUCC: Land Use Cover 149 Change. 
151 The MODISLC is derived from the Terra and Aqua combined Moderate Resolution Imaging 152 Spectroradiometer (MODIS) Land Cover Type (MCD12Q1) Version 6 data product, provides 153 global land cover types at yearly intervals from 2001 to 2017. The MODISLC V6 data products is 154 derived using supervised classifications then undergo additional post-processing that incorporate 155 prior knowledge and ancillary information to further refine specific classes [17]. The GlobeLand30 156 land cover datasets were derived from National Geomatics Center of China (NGCC) is the $30 \mathrm{~m}$

157 GLC data product of the years 2000 and 2010. The images utilized for GlobeLand30 classification 158 are multispectral images with 30 meters, including the TM5 and ETM+ of America Land 159 Resources Satellite (Landsat) and the multispectral images of China Environmental Disaster 160 Alleviation Satellite (HJ-1) [18, 43]. The FROM-GLC is the first fine scale global map product 161 extracted from Landsat Thematic Mapper (TM) and Enhanced Thematic Mapper Plus (ETM+) 162 data with a spatial resolution of $30 \mathrm{~m}$, covering the years of 2010, 2015 and 2017 [15].

163 In this study, the MODISLC dataset was downloaded from U.S. Geological Survey Land 164 Processes Distributed Active Archive Center [44], the GlobeLand30 global land cover dataset was 165 downloaded from the National Geomatics Center of China [45], and the FROM-GLC was 166 downloaded from the Center for Earth System Science, Tsinghua University, China [46]. Detailed 167 characteristics of these three datasets are summarized in Table 1, and the detailed classification 168 schemes are individually listed in Tables 2,3 , and 4.

Table 1 Characteristics of the archive land cover products used in the study

\begin{tabular}{lccc}
\hline & MODISLC & GlobeLand30 & FROM-GLC \\
\hline Sensor & Terra and Aqua & TM5, ETM+, HJ-1 & TM/ETM+ \\
Acquisition time & $2001-2017$ & 2000, 2010 & $2010,2015,2017$ \\
$\begin{array}{l}\text { Classification } \\
\text { method }\end{array}$ & Supervised classification of & POK based classification & MLC, J4.8 decision tree, \\
& MODIS reflectance data & & RF, and SVM classifier
\end{tabular}




\section{Input data}

Classification

schemes

Thematic

resolution

Spatial resolution

Range

Projection

Accuracy

assessment

Overall accuracy
Update rate
Producer agency
7 Spectral bands

LST/NDVI

Normalized BRDF

Adjusted Reflectance

IGBP

17

$500 \mathrm{~m}$

Global

Sinusoidal

Cross validation

$75 \%$
6 months
LP DAAC

U.S. Geological Survey
20,000 Landsat and

Chinese

HJ-1 satellite images

GLC

10

$30 \mathrm{~m}$

Global

UTM_WGS84

Sample based validation

[17]
$80 \%$

10 years

National Geomatics Center

of China
[18, 43]
8929 scenes TM/ETM+ data

8929 scenes TM/ETM+ data

FAO and IGBP

First level: 8

Second level: 26

$30 \mathrm{~m}$

Global

UTM_WGS84

Globally systematic

unaligned

sampling strategy

$65.51 \%$

Unknown

Tsinghua University, China

Reference

[15]

(POK: Pixel-object-knowledge; MLC: Maximum likelihood classifier; RF: Random Forest; SVM: Support Vector Machine; LST: Land Surface Temperature; NDVI: Normalized Difference Vegetation Index; BRDF: Bidirectional Reflectance Distribution Function)

Table 2 Classification scheme and class description of the MODISLC

\begin{tabular}{|c|c|c|}
\hline Name & Value & $\begin{array}{c}\text { Description } \\
\end{array}$ \\
\hline Evergreen Needleleaf Forests & 1 & $\begin{array}{l}\text { Dominated by evergreen conifer trees (canopy }>2 \mathrm{~m} \text { ). Tree cover } \\
>>60 \% .\end{array}$ \\
\hline Evergreen Broadleaf Forests & 2 & $\begin{array}{c}\text { Dominated by evergreen broadleaf and palmate trees (canopy }>2 \mathrm{~m} \text { ). } \\
\text { Tree cover }>60 \%\end{array}$ \\
\hline $\begin{array}{c}\text { Deciduous Needleleaf } \\
\text { Forests* }\end{array}$ & 3 & $\begin{array}{l}\text { Dominated by deciduous Needleleaf (larch) trees (canopy }>2 \mathrm{~m} \text { ). Tree } \\
\text { cover }>60 \% .\end{array}$ \\
\hline Deciduous Broadleaf Forests & 4 & $\begin{array}{l}\text { Dominated by deciduous broadleaf trees (canopy }>2 \mathrm{~m} \text { ). Tree cover } \\
>>60 \% \text {. }\end{array}$ \\
\hline Mixed Forests & 5 & $\begin{array}{c}\text { Dominated by neither deciduous nor evergreen }(40-60 \% \text { of each) tree } \\
\text { type (canopy }>2 \mathrm{~m}) \text {. Tree cover }>60 \% \text {. }\end{array}$ \\
\hline Closed Shrublands ${ }^{*}$ & 6 & Dominated by woody perennials $(1-2 \mathrm{~m}$ height $)>60 \%$ cover. \\
\hline Open Shrublands* & 7 & Dominated by woody perennials ( $1-2 \mathrm{~m}$ height) $10-60 \%$ cover. \\
\hline Woody Savannas & 8 & Tree cover $30-60 \%$ (canopy $>2 \mathrm{~m})$ \\
\hline Savannas & 9 & Tree cover $10-30 \%$ (canopy $>2 \mathrm{~m}$ ). \\
\hline Grasslands & 10 & Dominated by herbaceous annuals $(<2 \mathrm{~m})$ \\
\hline Permanent Wetlands & 11 & $\begin{array}{c}\text { Permanently inundated lands with } 30-60 \% \text { water cover and }>10 \% \\
\text { vegetated cover. }\end{array}$ \\
\hline Croplands & 12 & At least $60 \%$ of area is cultivated cropland. \\
\hline Urban and Built-up Lands & 13 & $\begin{array}{c}\text { At least 30\% impervious surface area including building materials, } \\
\text { asphalt, and vehicles. }\end{array}$ \\
\hline $\begin{array}{c}\text { Cropland/Natural Vegetation } \\
\text { Mosaics }\end{array}$ & 14 & $\begin{array}{l}\text { Mosaics of small-scale cultivation } 40-60 \% \text { with natural tree, shrub, or } \\
\text { herbaceous vegetation. }\end{array}$ \\
\hline Permanent Snow and Ice & 15 & $\begin{array}{c}\text { At least } 60 \% \text { of area is covered by snow and ice for at least } 10 \text { months } \\
\text { of the year. }\end{array}$ \\
\hline Barren & 16 & $\begin{array}{c}\text { At least } 60 \% \text { of area is non-vegetated barren (sand, rock, soil) areas } \\
\text { with less than } 10 \% \text { vegetation. }\end{array}$ \\
\hline Water Bodies & 17 & At least $60 \%$ of area is covered by permanent water bodies. \\
\hline
\end{tabular}


*Land cover categories not present in the study area.

Table 3 Classification schemes and class description of the GlobeLand30 land cover products

\begin{tabular}{|c|c|c|}
\hline Land cover types & Value & Description \\
\hline Cultivated Land & 10 & $\begin{array}{l}\text { Lands used for agriculture, horticulture and gardens, including paddy } \\
\text { fields, irrigated and dry farmland, vegetation and fruit gardens, etc. }\end{array}$ \\
\hline Forest & 20 & $\begin{array}{l}\text { Lands covered with trees, with vegetation cover over } 30 \% \text {, including } \\
\text { deciduous and coniferous forests, and sparse woodland with cover } 10 \text { - } \\
30 \% \text {, etc. }\end{array}$ \\
\hline Grassland & 30 & Lands covered by natural grass with cover over $10 \%$, etc. \\
\hline Shrub lands & 40 & $\begin{array}{l}\text { Lands covered with shrubs with cover over } 30 \% \text {, including deciduous } \\
\text { and evergreen shrubs, and desert steppe with cover over } 10 \% \text {, etc. }\end{array}$ \\
\hline Wetland & 50 & $\begin{array}{l}\text { Lands covered with wetland plants and water bodies, including inland } \\
\text { marsh, lake marsh, river floodplain wetland, forest/shrub wetland, peat } \\
\text { bogs, mangrove and salt marsh, etc. }\end{array}$ \\
\hline Water bodies & 60 & $\begin{array}{c}\text { Water bodies in the land area, including river, lake, reservoir, fish } \\
\text { pond, etc. }\end{array}$ \\
\hline Tundra* & 70 & $\begin{array}{l}\text { Lands covered by lichen, moss, hardy perennial herb and shrubs in the } \\
\text { polar regions, including shrub tundra, herbaceous tundra, wet tundra } \\
\text { and barren tundra, etc. }\end{array}$ \\
\hline Artificial Surfaces & 80 & $\begin{array}{l}\text { Lands modified by human activities, including all kinds of habitation, } \\
\text { industrial and mining area, transportation facilities, and interior urban } \\
\text { green zones and water bodies, etc. }\end{array}$ \\
\hline Bareland & 90 & $\begin{array}{l}\text { Lands with vegetation cover lower than } 10 \% \text {, including desert, sandy } \\
\text { fields, Gobi, bare rocks, saline and alkaline lands, etc. }\end{array}$ \\
\hline $\begin{array}{l}\text { Permanent snow and } \\
\text { ice }^{*}\end{array}$ & 100 & Lands covered by permanent snow, glacier and icecap \\
\hline Not classified & 255 & Has not received a map label because of missing inputs. \\
\hline
\end{tabular}

Table 4 Classification Scheme of the FROM-GLC land cover products

\begin{tabular}{|c|c|c|c|c|c|c|c|c|c|c|c|}
\hline L1T & $\begin{array}{l}\text { L1 } \\
\text { C }\end{array}$ & L2T & L1/2C & L2T & L1/2C & L2T & $\begin{array}{c}\mathrm{L} 1 / 2 \\
\mathrm{C}\end{array}$ & L2T & $\begin{array}{c}\mathrm{L1} / \mathbf{2} \\
\mathrm{C}\end{array}$ & L2T & $\begin{array}{c}\mathrm{L} 1 / 2 \\
\mathrm{C}\end{array}$ \\
\hline Crop & 10 & Rice & $10 / 11$ & Greenhouse & $10 / 12$ & Other & $10 / 13$ & & & & \\
\hline Forest & 20 & Broadleaf & $20 / 21$ & Needleleaf & $20 / 22$ & Mixed & $20 / 23$ & Orchard & $20 / 24$ & & \\
\hline Grass & 30 & Managed & $30 / 31$ & Nature & $30 / 32$ & & & & & & \\
\hline Shrub & 40 & & & & & & & & & & \\
\hline Wetland & 50 & Grass & $30 / 51$ & Silt & $90 / 52$ & & & & & & \\
\hline Water & 60 & Lake & $60 / 61$ & Pond & $60 / 62$ & River & $60 / 63$ & Sea & $60 / 64$ & & \\
\hline Tundra* & 70 & Shrub & $40 / 71$ & Grass & $30 / 72$ & & & & & & \\
\hline Impervious & 80 & $\begin{array}{l}\text { High } \\
\text { albedo }\end{array}$ & $80 / 81$ & Low albedo & $80 / 82$ & & & & & & \\
\hline Bareland & 90 & $\begin{array}{l}\text { Saline- } \\
\text { Alkali }\end{array}$ & 90/91 & Sand & 90/92 & Gravel & 90/93 & $\begin{array}{l}\text { Bare- } \\
\text { Croplan } \\
\text { d }\end{array}$ & $10 / 94$ & $\begin{array}{l}\text { Dry } \\
\text { river/la } \\
\text { ke bed }\end{array}$ & 90/95 \\
\hline $\begin{array}{l}\text { Snow/Ice* } \\
\text { Cloud }\end{array}$ & $\begin{array}{l}100 \\
120\end{array}$ & Snow $^{*}$ & 100/101 & Ice* & $100 / 102$ & & & & & & \\
\hline
\end{tabular}


181 Remote sensing satellite imageries were used to identify the land use and land cover (LULC) class

182 of the study area in some selective years of study. The images were acquired for 2001, 2005, and

1832010 in between January and March of the year from Landsat 5 Thematic Mapper (TM L1T).

184 While in March 2015 and February 2017 of images were acquired from Landsat 8 OLI. All these 185 data were downloaded from the USGS Global Visualization Viewer (GloVis) archive 186 (https://glovis.usgs.gov/) [47]. The downloaded bands of Landsat 8 OLI and TM scenes were 187 superimposed (excluding the thermal band) to form multispectral images using ENVI5.1 software. 188 After the acquisition of the images, seven bands of OLI8 and five bands of TM except the thermal 189 bands of each image scene were superimposed to form a single multispectral image dataset using 190 the layer stack function. From the acquired data, if possible, only those images without cloud cover 191 were selected. Different remote sensing and GIS techniques were applied, such as digital image 192 processing using supervised classification and image indices. Supervised classification using a 193 maximum likelihood algorithm was applied to classify the LULC map. The classified images were 194 modified with the help of image indices and visual interpretation to produce a more accurate map. 195 Based on IGBP-9, FAO land cover classes and visible land cover of the study, we adopted a 196 classification scheme consisting of 6 first level classes, namely water, forests, wetlands, croplands, 197 artificial surfaces and others/bare lands (Table 5). The Universal Traverse Mercator (UTM) system 198 with the datum of WGS84 and Zone 46N was selected as projection for all data.

199 Table 5 Classification schemes for LULC class distribution of 30m Landsat TM/ETM+ imaginary data

\begin{tabular}{ccc}
\hline Land cover types & Value & Description \\
\hline Water & 1 & Water bodies in the land area, including river, lake, reservoir, fish \\
pond, sea water etc.
\end{tabular}




$\begin{array}{ccc}\begin{array}{c}\text { Wetlands } \\ \text { Croplands }\end{array} & \begin{array}{r}\text { Lands covered with wetland plants and water bodies, including inland } \\ \text { marsh, lake marsh, river floodplain wetland, forest/shrub wetland, peat } \\ \text { bogs, mangrove and salt marsh, etc. }\end{array} \\ \begin{array}{l}\text { Artificial Surfaces } \\ \text { Lands used for agriculture, horticulture and gardens, including paddy } \\ \text { fields, irrigated and dry farmland, vegetation and fruit gardens, etc. } \\ \text { Lands modified by human activities, including all kinds of habitation, } \\ \text { industrial and mining area, transportation facilities, and interior urban } \\ \text { green zones and water bodies, etc. }\end{array} \\ \text { Lthers/Bare lands } \\ 6\end{array}$

2.3 Methodology

\subsubsection{Classification system conversion}

202 The land cover datasets of MODISLC, GlobeLand30, FROM-GLC, and LULC classes are used

203 different classification schemes as well as common classification system of IGBP for MODISLC

204 [17], combined IGBP and FAO for FROM-GLC [15], and unique classification for GlobeLand30

205 [18] and LULC class distribution. However, differences in the classification system are prominent

206 (Table 2, 3, 4, and 5), for example, the FROM-GLC, GlobeLand30 and LULC class are the product

207 in which no distinction is made between evergreen and deciduous forest classes, while the LULC

208 is the only product in which no identification is made of shrublands and grasslands and MODISLC

209 is the only product having closed and open shrublands. To overcome the problem of conflicting

210 classification systems, the thematic classification system of the MODISLC,GlobeLand30,FROM-

211 GLCand the Landsat classified images as LULC were converted into four common classification

212 systems based on their original definition of classes in each land cover product, which defaults to

213 selecting the dominant category [11,20,22,24-26,48]. When some categories from the original

214 classification systems could not completely be attributed into any category in the common

215 classification systems due to conflicting definitions, we classified them into corresponding types

216 based on knowledge or by referring to data like the DEM, and labeled them as ambiguous types in 
217 this study resulting in uncertainties during classification system conversion [48]. The IGBP-17,

218 IGBP-9, IPCC-5 and TC common classification systems were used in this study. The detailed

219 categories of the common classification systems and corresponding relationships were presented

220 in Table 6.

221

222

Table 6 The converting classification schemes of the MODISLC, GlobeLand30, FROM-GLC, and LULC classes in 223 the four common classification systems

\begin{tabular}{|c|c|c|c|c|}
\hline MODISLC & GlobeLand30 & FROM-GLC & LULC & IGBP-17 \\
\hline 17 & 60 & $61,62,63,64$ & 1 & 1 Water \\
\hline 1 & & 22 & & $\begin{array}{c}2 \text { Evergreen Needleleaf Forest } \\
(\text { Coverage }>60 \% \text { and Height }>2 \mathrm{~m})\end{array}$ \\
\hline 2 & & 21 & & $\begin{array}{c}3 \text { Evergreen Broadleaf Forest } \\
(\text { Coverage }>60 \% \text { and Height }>2 \mathrm{~m})\end{array}$ \\
\hline $3^{*}$ & & & & $\begin{array}{c}4 \text { Deciduous Needleleaf Forest } \\
(\text { Coverage }>60 \% \text { and Height }>2 \mathrm{~m})\end{array}$ \\
\hline 4 & & & & $\begin{array}{c}5 \text { Deciduous Broadleaf Forest } \\
(\text { Coverage }>60 \% \text { and Height }>2 \mathrm{~m})\end{array}$ \\
\hline 5 & 20 & 23 & 2 & 6 Mixed Forests \\
\hline $6^{*}$ & & & & $\begin{array}{c}7 \text { Closed Shrublands (Coverage }>60 \% \\
\text { and } \\
\text { Height }<2 \mathrm{~m})\end{array}$ \\
\hline $7^{*}$ & 40 & 40 & & $\begin{array}{c}8 \text { Open Shrublands } \\
(10 \%<\text { Coverage }<60 \% \text { and Height }<2 \\
\mathrm{m})\end{array}$ \\
\hline 8 & & & & $\begin{array}{c}9 \text { Woody Savannas } \\
(30 \%<\text { Coverage }<60 \% \text { and Height }>2 \\
\mathrm{m})\end{array}$ \\
\hline 9 & & & & $\begin{array}{c}10 \text { Savannas }(10 \%<\text { Coverage }<30 \% \text { and } \\
\text { Height }>2 \mathrm{~m})\end{array}$ \\
\hline 10 & 30 & $31,32,51$ & & 11 Grasslands \\
\hline 11 & 50 & 50 & 3 & $\begin{array}{l}12 \text { Permanent Wetland (transition zone } \\
\text { between land and water bodies) }\end{array}$ \\
\hline 12 & 10 & $11,12,13$ & 4 & 13 Croplands \\
\hline 13 & 80 & $80,81,82$ & 5 & 14 Urban and Built-Up \\
\hline 14 & & 94 & & $\begin{array}{l}15 \text { Cropland/Natural Vegetation Mosaic } \\
\text { (Any type of coverage }<60 \% \text { ) }\end{array}$ \\
\hline $15^{*}$ & $100^{*}$ & 101,102 & & 16 Snow and Ice \\
\hline 16 & 90 & $91,92,93,95,52$ & 6 & $\begin{array}{c}17 \text { Barren or Sparsely Vegetated } \\
(\text { Coverage }<10 \%)\end{array}$ \\
\hline MODISLC & GlobeLand30 & FROM-GLC & LULC & IGBP-9 \\
\hline 17 & 60 & $61,62,63,64$ & 1 & 1 Water \\
\hline $\begin{array}{c}1,2,3^{*}, 4,5 \\
8\end{array}$ & 20 & $21,22,23$ & 2 & 2 Forests \\
\hline $6^{*}, 7^{*}$ & $40,70^{*}$ & 40 & & 3 Shrublands \\
\hline 9,10 & 30 & 32 & & 4 Grasslands \\
\hline 11 & 50 & 51,52 & 3 & 5 Permanent Wetland \\
\hline 12,14 & 10 & $11,13,94$ & 4 & 6 Croplands (Crop/vegetation) \\
\hline
\end{tabular}




\begin{tabular}{|c|c|c|c|c|}
\hline 13 & 80 & $80,81,82$ & 5 & 7 Urban and Built-Up \\
\hline $15^{*}$ & $100^{*}$ & $101^{*}, 102^{*}$ & & 8 Snow and Ice \\
\hline 16 & 90 & $91,92,93,95$ & 6 & 9 Others \\
\hline MODISLC & GlobeLand30 & FROM-GLC & LULC & IPCC-5 classes \\
\hline 12,14 & 10 & $11,13,94$ & 4 & 1 Croplands \\
\hline $\begin{array}{l}1,2,3^{*}, 4,5, \\
6^{*}, 7^{*}, 8\end{array}$ & 20 & $21,22,23,40$ & 2 & 2 Forest lands \\
\hline 9,10 & 30 & 32 & & 3 Grasslands \\
\hline $11,15^{*}, 17$ & $60,100^{*}$ & $\begin{array}{c}61,62,63,64,51, \\
52,101^{*}, 102^{*}\end{array}$ & 1,3 & 4 Water, snow, ice and wetland \\
\hline 13,16 & $40,50,70^{*}, 80,90$ & $\begin{array}{c}80,81,82,91,92 \\
93,95\end{array}$ & 5,6 & 5 Others \\
\hline MODISLC & GlobeLand30 & FROM-GLC & LULC & TC \\
\hline $\begin{array}{c}1,2,3^{*}, 4,5, \\
6^{*}, 7^{*}, 8,9 \\
10,12,14\end{array}$ & $10,20,30$ & $\begin{array}{c}11,13,94,21,22, \\
23,40,32\end{array}$ & 2,4 & 1 Vegetation \\
\hline $11,15^{*}, 17$ & $60,100^{*}$ & $\begin{array}{c}61,62,63,64,51 \\
52,101^{*}, 102^{*}\end{array}$ & 1,3 & 2 Water, snow, ice and wetland \\
\hline 13,16 & $40,50,70^{*}, 80,90$ & $\begin{array}{c}80,81,82,91,92 \\
93,95\end{array}$ & 5,6 & 3 Others \\
\hline
\end{tabular}

*Uncertain types when conversion was performed

\subsubsection{Uncertainty during the classification system conversion}

226 The classification schemes of the FROM-GLC, GlobeLand30, MODISLC and Landsat LULC

227 datasets were converted into the four common classification systems. During the classification

228 system conversion, some categories from the original classification systems could not completely

229 be attributed into any category in the common classification systems due to differences in class

230 definitions which were labeled as ambiguous types in this study. These were summarized into four

231 main ambiguous types during classification system conversion, including (1) no dominant type;

232 (2) different percentage of the dominant type; (3) the type definition broader than the

233 corresponding type in the common classification system; and (4) labeling errors [48].

234 Uncertainties of classification system conversion caused by ambiguous types in the four 235 common classification systems were quantitatively calculated by the following equation [48]:

$$
U=\frac{N_{j}}{\sum_{i}^{n} N_{i}} \times 100
$$


237 Where, $U=$ the uncertainty ratio caused by classification system conversion due to ambiguous types; $N_{j}=$ 238 the total number of pixels of ambiguous types, $n=$ the number of land cover types in the common 239 classification system, $N_{i}=$ the total number of pixels of one type of common classification system, and $240 \quad \sum_{i}^{n} N_{i}=$ the total number of pixels of all land cover types.

\subsubsection{The method for assessing areal and spatial inconsistency}

242 Areal and spatial inconsistencies were assessed using pixel-by-pixel comparisons between the 243 different land cover products in the common classification systems.

244 Areal Inconsistency of each Class (AIC) and Overall Areal Inconsistency (OAI) in four common 245 classification systems were computed by the following equations [20, 48]:

$$
A I C=A B S\left(X_{i}-Y_{i}\right) / 2
$$

$$
O A I=\sum_{i}^{n} A I C
$$

249 where, $A I C=$ areal inconsistencies of each class; $n=$ the total number of land use types in the common 250 classification systems; $X_{i}=$ total area percentage of land use type $i$ in one of the FROM-GLC, the 251 GlobeLand30, the MODISLC, and the LULC; $Y_{i}=$ total area percentage of class $i$ one other four land cover 252 products; and $O A I=$ overall areal inconsistency in the common classification systems.

253 Using the four common classification systems, the first step for obtaining the pairwise spatial 254 inconsistencies between the FROM-GLC (30 m), GlobeLand30 (30 m), LULC of remote sensing 255 images (30 m), and MODISLC (500 m) datasets level involved up-scaling higher spatial resolution 256 land cover into the corresponding datasets lower spatial resolution. A pixel in a low spatial 257 resolution usually represents only one type of land use type, whereas the corresponding high spatial 258 resolution pixel includes more than one land use type. In this study, a low spatial resolution pixel 259 was considered to be $100 \%$ correct when it agreed with the dominant type of the corresponding

260 high spatial resolution pixels and was considered to be $0 \%$ correct when it disagreed. Majority 
261 filtering technology was used to upscale the high spatial resolution land cover into lower 262 resolutions. The Overall Spatial Inconsistency (OSI) between a given pair of these four land cover 263 products was calculated according to the formula below [20, 48]:

$$
O S I=\frac{N_{(i \neq j)}}{N} \times 100
$$

265 Where, $O S I=$ Overall Spatial Inconsistency; $N_{(i \neq j)}=$ the number of pixels for which the type is different from 266 another one at the same location when compared to different datasets (either FROM-GLC, GlobeLand30, 267 LULC, or MODISLC), and $N=$ the total number of pixels.

\subsubsection{Determination of land use classification system}

269 Different classification schemes were used in different land cover products of the MODISLC, the

270 GlobeLand30, and the FROM-GLC datasets (Tables 2, 3, 4). In addition to image classification, a 271 supervised classification method combined of IGBP and IPCC was used to build-up LULC map 272 as a unique classification scheme (Table 5). All land classes of interest were selected and carefully

273 defined to classify remotely sensed data successfully into land use and land cover categories in the 274 study area. This requires the use of a classification scheme containing taxonomically clear 275 definitions of classes. Classes in the system should normally be mutually exclusive, exhaustive, 276 and hierarchical [49]. International Geosphere-Biosphere Program (IGBP) suggested nine broad 277 categories for representing land areas within a country: water; forests; shrublands; grasslands; 278 permanent wetland; croplands; urban and built-up; snow and ice; and others [10,48]. Based on 279 these land use frames, the land areas in this study were classified/ reclassified as water, forests, 280 grasslands, permanent wetland, croplands, urban and built-up/ artificial surface, and others/bare 281 land, through field observation and by referencing preceding reports [34,36]. Each class is 
282 considered sufficiently representative and includes all land area within the study area, reducing

283 possible overlaps and omissions as far as practicable.

\section{Results}

\subsection{Areal Inconsistency}

286 Using four common classification systems, the areal inconsistencies of each land use type from

287 pairwise comparisons of the FROM-GLC, GlobeLand30, MODISLC, and LULC datasets were

288 shown in Table 7. During the classification system conversion to IGBP-17, the areal

289 inconsistencies were mainly present in mixed forests (up to 24.56\%), woody savannas (up to

$29013.57 \%$ ) and urban and built-up (up to 13.43\%) classes. The areal inconsistencies in classification

291 system conversion to IGBP-9 were mainly caused by urban and built-up, croplands, and grasslands

292 (up to $12.35 \%, 7.90 \%$, and $6.85 \%$ respectively) classes. During the classification system

293 conversion to IPCC-5, the areal inconsistencies were mainly caused by croplands, grassland, and

294 others (up to $7.90 \%, 6.85 \%$, and $13.55 \%$ respectively). Mean while, during the classification

295 system conversion to TC system, the areal inconsistencies were mainly caused by vegetation (up

296 to $16.19 \%$ ) and others (up to $13.55 \%$ ). These land cover types were the dominant types in our

297 study area, illustrating that the different percentages of dominant types among land cover products

298 can greatly influence areal inconsistencies. The areal inconsistency of forests using IGBP-17,

299 IGBP-9, and IPCC-5 (24.56\%, 4.87\%, and 5.39\% respectively) between the FROM-GLC and the

300 MODISLC were higher than the inconsistent result $(0.2 \%, 1.33 \%$, and $1.48 \%)$ from the paper [48],

301 but the areal inconsistencies for vegetation using TC (2.57\%) was far less than the result $(40.21 \%)$

302 in the paper mentioned above. 
303

304

Table 7 Areal inconsistencies for each land use type in four common classification systems in pair wise comparisons of the FROM-GLC, GlobeLand30, MODISLC, and Landsat TM/ETM LULC datasets.

\begin{tabular}{|c|c|c|c|c|c|c|c|}
\hline $\begin{array}{c}\text { Classification } \\
\text { System }\end{array}$ & Type & $\begin{array}{c}\text { FG-GL } \\
(\%)\end{array}$ & $\begin{array}{c}\text { FG-MOD } \\
(\%)\end{array}$ & $\begin{array}{c}\text { FG-LU } \\
(\%)\end{array}$ & $\begin{array}{c}\text { GL-MOD } \\
(\%)\end{array}$ & $\begin{array}{c}\text { GL-LU } \\
(\%)\end{array}$ & $\begin{array}{c}\text { MOD-LU } \\
(\%)\end{array}$ \\
\hline \multirow{17}{*}{ IGBP-17 } & 1 & 0.95 & 0.7 & 0.97 & 1.65 & 0.03 & 1.67 \\
\hline & 2 & 0 & 0.01 & 0 & 0.01 & 0 & 0.01 \\
\hline & 3 & 0 & 3.25 & 0 & 3.25 & 0 & 3.25 \\
\hline & 4 & 0 & 0 & 0 & 0 & 0 & 0 \\
\hline & 5 & 0 & 2.87 & 0 & 2.87 & 0 & 2.87 \\
\hline & 6 & 4.09 & 24.56 & 5.94 & 20.47 & 1.85 & 18.62 \\
\hline & 7 & 0 & 0 & 0 & 0 & 0 & 0 \\
\hline & 8 & 0.02 & 0.52 & 0.52 & 0.5 & 0.5 & 0 \\
\hline & 9 & 0 & 13.57 & 0 & 13.57 & 0 & 13.57 \\
\hline & 10 & 0 & 5.31 & 0 & 5.31 & 0 & 5.31 \\
\hline & 11 & 0.92 & 0.29 & 1.83 & 0.63 & 0.91 & 1.54 \\
\hline & 12 & 1.27 & 3.08 & 4.83 & 1.81 & 3.56 & 1.75 \\
\hline & 13 & 0.615 & 5.92 & 7.9 & 5.3 & 7.29 & 1.99 \\
\hline & 14 & 5.6 & 1.08 & 12.35 & 6.68 & 6.75 & 13.43 \\
\hline & 15 & 0 & 3.71 & 0 & 3.71 & 0 & 3.71 \\
\hline & 16 & 0 & 0 & 0 & 0 & 0 & 0 \\
\hline & 17 & 0.27 & 0.14 & 0.02 & 0.13 & 0.25 & 0.12 \\
\hline \multirow{9}{*}{ IGBP-9 } & 1 & 0.95 & 0.7 & 0.97 & 1.65 & 0.03 & 1.67 \\
\hline & 2 & 4.09 & 4.87 & 5.94 & 0.78 & 1.85 & 1.07 \\
\hline & 3 & 0.02 & 0.52 & 0.52 & 0.5 & 0.5 & 0 \\
\hline & 4 & 0.92 & 5.02 & 1.83 & 5.94 & 0.91 & 6.85 \\
\hline & 5 & 1.27 & 3.08 & 4.83 & 1.81 & 3.56 & 1.75 \\
\hline & 6 & 0.62 & 2.21 & 7.9 & 1.59 & 7.29 & 5.7 \\
\hline & 7 & 5.6 & 1.08 & 12.35 & 6.68 & 6.75 & 13.43 \\
\hline & 8 & 0 & 0 & 0 & 0 & 0 & 0 \\
\hline & 9 & 0.27 & 0.14 & 0.02 & 0.13 & 0.25 & 0.12 \\
\hline \multirow{5}{*}{ IPCC-5 } & 1 & 0.62 & 2.21 & 7.9 & 1.59 & 7.29 & 5.7 \\
\hline & 2 & 4.61 & 5.39 & 6.46 & 0.78 & 1.85 & 1.07 \\
\hline & 3 & 0.92 & 5.02 & 1.83 & 5.94 & 0.91 & 6.85 \\
\hline & 4 & 1.14 & 3.78 & 3.86 & 4.92 & 4.99 & 0.08 \\
\hline & 5 & 7.29 & 1.22 & 12.33 & 8.5 & 5.05 & 13.55 \\
\hline \multirow{3}{*}{ TC } & 1 & 6.15 & 2.57 & 16.19 & 3.58 & 10.04 & 13.62 \\
\hline & 2 & 1.14 & 3.78 & 3.86 & 4.92 & 4.99 & 0.08 \\
\hline & 3 & 7.29 & 1.22 & 12.33 & 8.5 & 5.05 & 13.55 \\
\hline
\end{tabular}

(FG: FROM-GLC datasets; GL: GlobeLand30 datasets; MOD: MODISLC datasets; and LU: LULC of Landsat TM/ETM+ datasets) 
Overall areal inconsistencies between pairs of the FROM-GLC, GlobeLand30, MODISLC and

308 LULC of Landsat images in four common classification systems are shown in the Fig. 3. Areal

309 inconsistencies decreased with the increasing level of aggregation of the classification system,

310 from IGBP-17 to TC as the higher areal inconsistencies were appeared IGBP-17 class conversion

311 and smallest was found in TC.

312 The largest overall areal inconsistency appeared in between the MODISLC and LULC of 313 Landsat images aggregation using the common classification system IGBP-17 to TC (33.92\%,

$31415.30 \%, 13.63 \%$, and $13.63 \%$ respectively) and the smallest in between the FROM-GLC and 315 GlobeLand30 (6.87\%, 6.87\%, 7.29\%, and 7.29\% respectively). The pairwise inconsistencies were 316 higher in related to MODISLC, indicating the accuracy of land cover datasets are depended on 317 spatial resolution of the products.

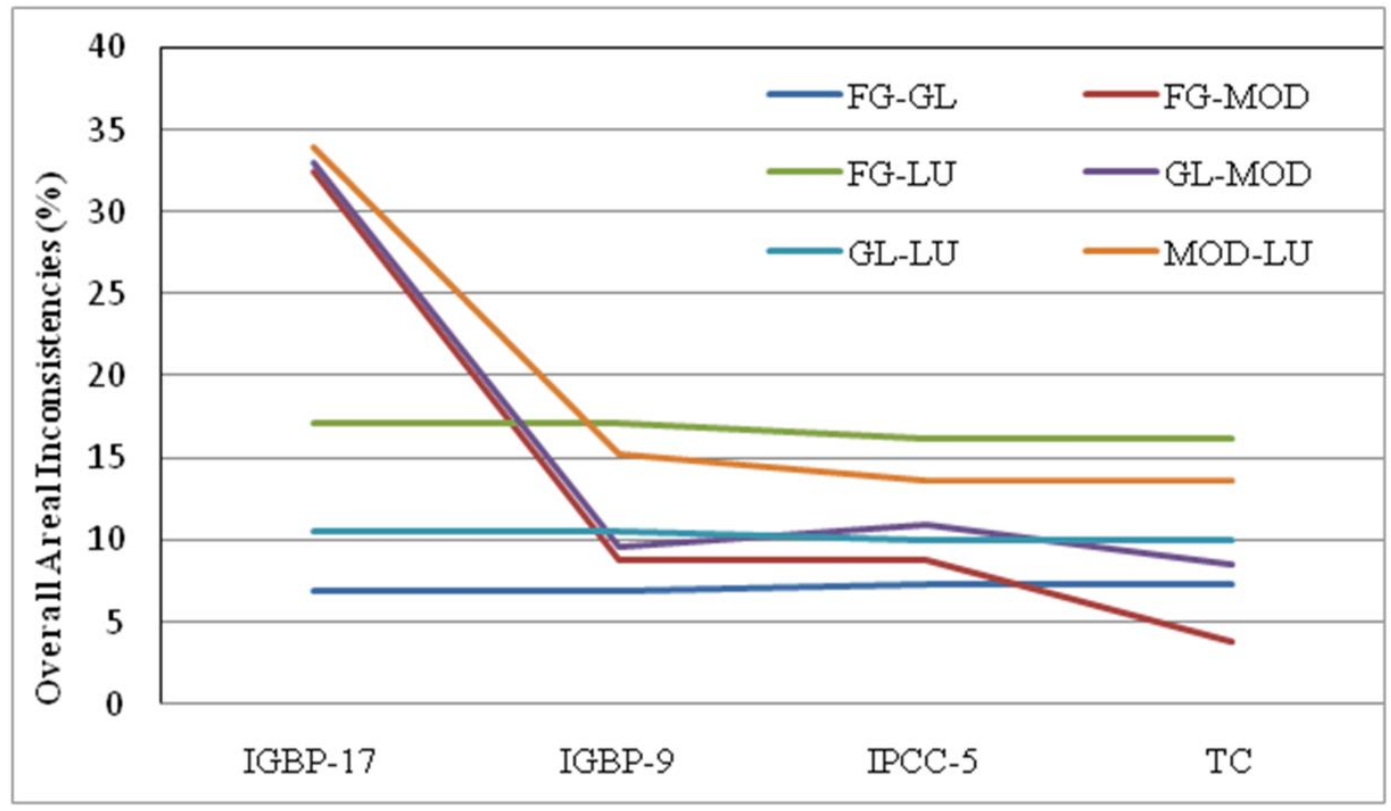

Fig. 3 Overall areal inconsistencies between pairwise of the FROM-GLC, GlobeLand30, MODISLC, and LULC class of Landsat TM/ETM+ datasets in four common classification systems (FG: FROM-GLC datasets; GL: 
324 The distribution and overall spatial inconsistencies in the pairwise comparisons of the FROM-

325 GLC, GlobeLand30, MODISLC, and LULC datasets are shown in Fig. 4. The overall smallest

326 spatial inconsistencies were between the FROM-GLC and the GlobeLand30 datasets as $16.16 \%$,

$32715.61 \%, 12.93 \%$, and $8.91 \%$ using the aggregation of common classification systems IGBP-17,

328 IGBP-9, IPCC-5 and TC, respectively. While the overall higher spatial inconsistencies in

329 comparison to other pair of land cover datasets were between the LULC and MODISLC as of

$33033.75 \%, 17.80 \%, 21.66 \%$, and $13.97 \%$ using the four common classification systems respectively.

331 In addition, the overall spatial inconsistency in IGBP-17 classification system between the FROM-

332 GLC and MODISLC (33.23\%) was slightly higher than the inconsistent result (18.57\%) from the

333 paper [48], but the overall spatial inconsistencies in the classification systems IGBP-9, IPCC-5,

334 and TC $(16.05 \%, 12.79 \%$, and $4.33 \%$ respectively) were slightly less than the results $(18.05 \%$,

$33517.44 \%$, and $14.95 \%$ respectively) in the paper mentioned above. The spatial inconsistencies

336 decreased with the increasing level of aggregation of common classification systems from IGBP-

33717 to TC.

338 According to Fig. 4, the spatial inconsistencies in the pairwise comparison related to

339 MODISLC were slightly higher than all other pairs of land cover datasets in IGBP-17, while they

340 were smallest in TC classification system. On the other, the decreasing rates of overall spatial

341 inconsistencies were lowest in the pairwise comparison related to LULC with the increasing level

342 of aggregation. The overall spatial inconsistencies in pairwise comparison were almost regular

343 results in IGBP-9 common classification system and as identified the better classification system

344 in representing the study area land use and land cover change. 

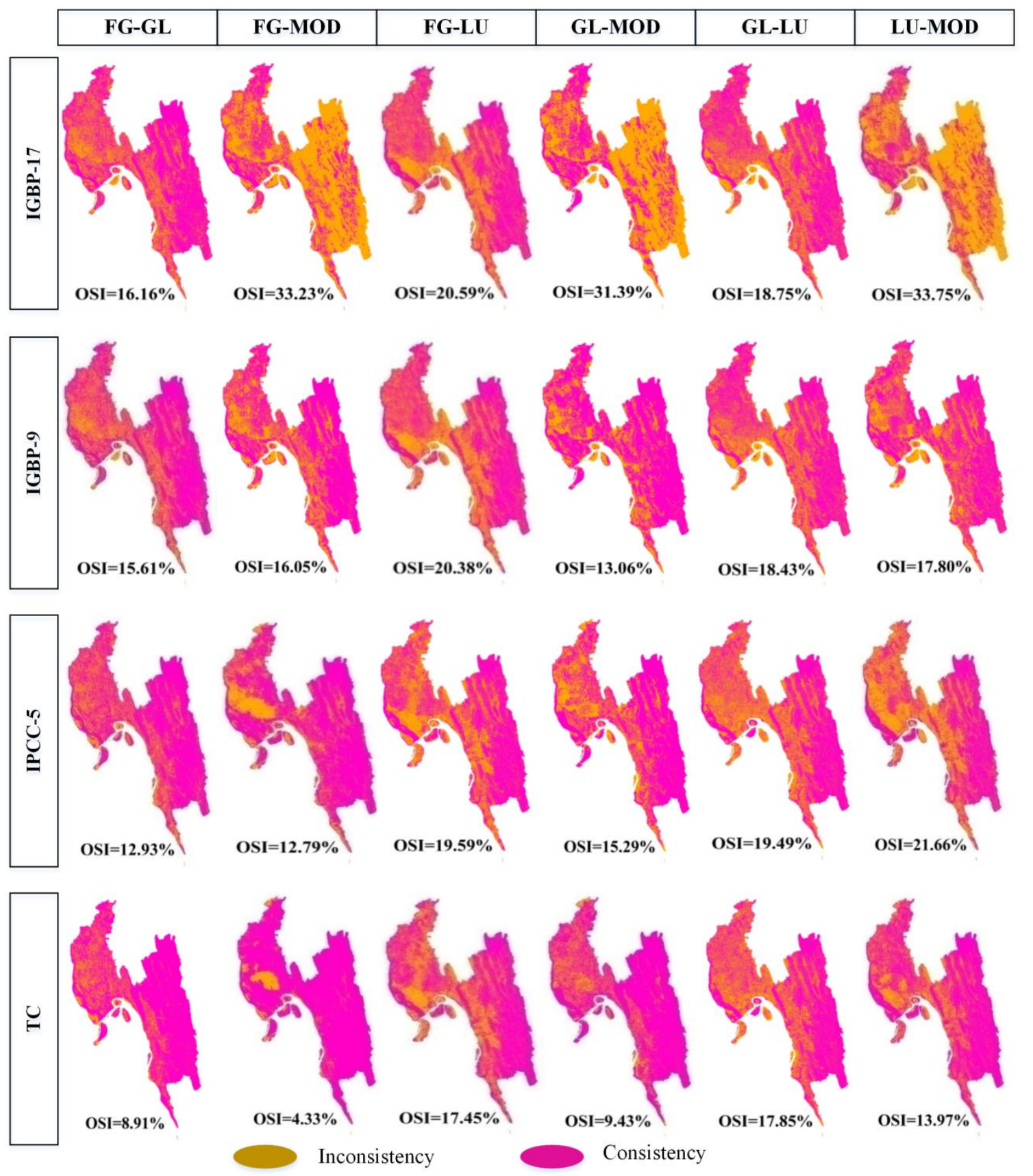

346 Fig.4 Overall spatial inconsistencies (OSI) in the pairwise comparison of FROM-GLC, GlobeLand30, MODISLC, 347 and LULC datasets in the four common classification systems (FG: FROM-GLC datasets; GL: GlobeLand30 348 datasets; MOD: MODISLC datasets; and LU: Land use and land cover classes of remote sensing imaginary datasets)

\subsection{Land Use Classification} are summarized in Fig. 5. This table is a combined result of land use classification of Landsat 
352 satellite images as LULC and different land cover products of the FROM-GLC, the Globeland30,

353 and the MODISLC datasets. The areas were arranged by some specific year (2001, 2005, 2010,

3542015 , and 2017) and by land use sub-categories based on IGBP-9 classification system as of lowest

355 variation of overall areal and spatial inconsistencies were identified in Fig. 3 and 4. As of 2017,

356 forests (lands covered with trees, with vegetation cover including deciduous and coniferous

357 forests, and sparse woodland) dominated the land cover of this region; comprising $40.2 \%, 50 \%$,

358 and $31.7 \%$ of the total land cover area by MODISLC, FROM-GLC, and LULC respectively. In

359 the GlobeLand30 land cover dataset, the same feature was the dominant category in their recent

360 (2010) product as $42.6 \%$ of the total land cover area. Croplands (lands used for agriculture,

361 horticulture and gardens, including paddy fields, irrigated and dry farmland, vegetation and fruit

362 gardens, etc.) were the second dominant land cover class, covering approximately $30.4 \%, 34.8 \%$,

$36323.8 \%$, and $32.2 \%$ in the datasets respectively MODISLC, FROM-GLC, LULC, and GlobeLand30

364 of the land. Grasslands, occupying 4914 sq. km in MODISLC, 1461 sq. km in FROM-GLC, and

$365907 \mathrm{sq} . \mathrm{km}$ in Globeland30 datasets of the land area, appears around the transition zone and was

366 not identified in LULC class. Because of their similar spectral reflectance signatures, it was

367 difficult to definitely differentiate grasslands from agriculture on Landsat images. 

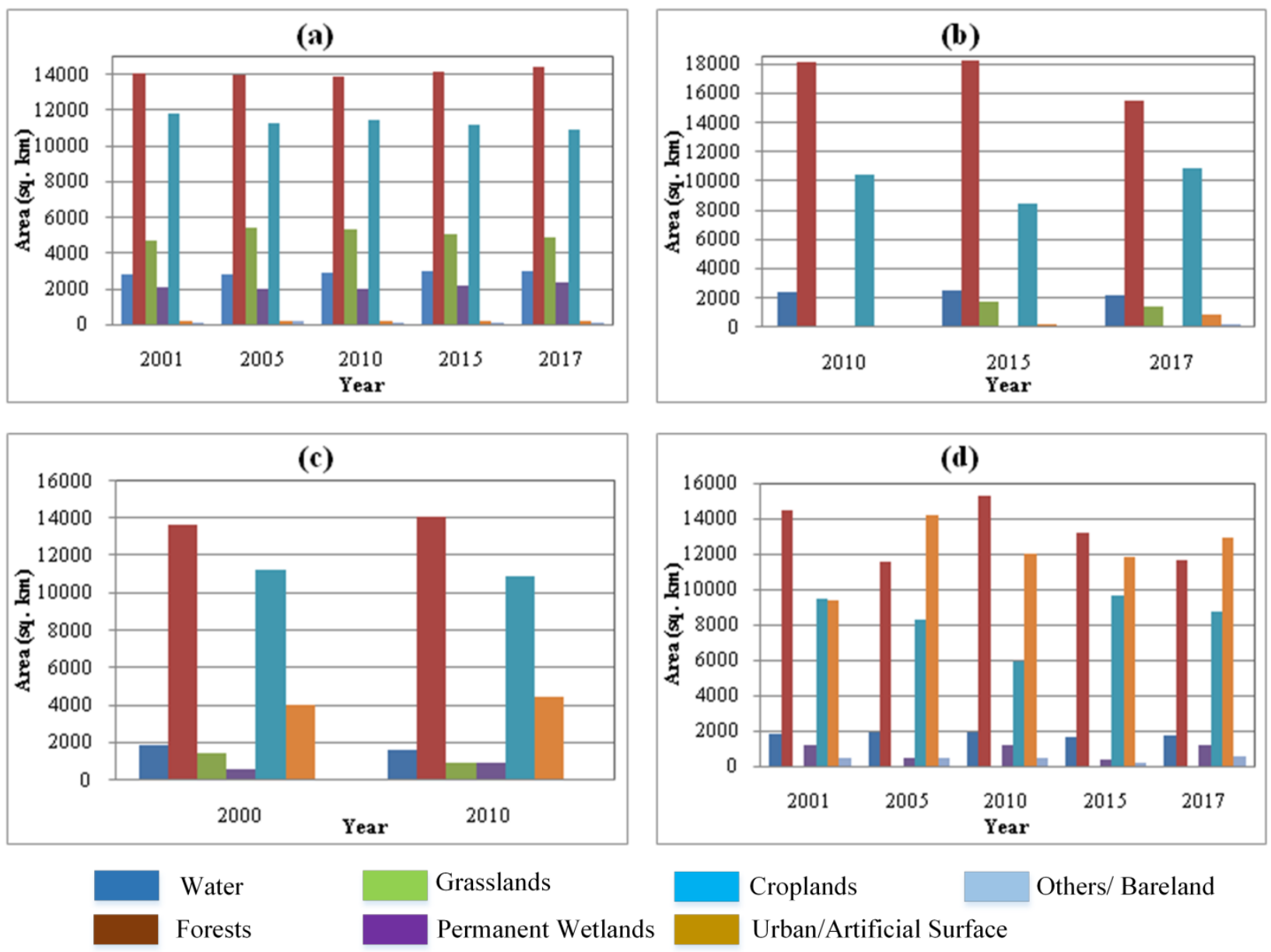

Fig. 5 Land use classification of the southeastern region of Bangladesh from (a) MODISLC, (b) FROM-GLC, (c) GlobeLand30, and (d) LULC of Landsat satellite images

373 the MODISLC in the year 2001, 2005, 2010, 2015 and 2017, the Globeland30 in the year 2000 374 and 2010, and the FROM-GLC in the year 2010, 2015 and 2017 were extracted. Based on 375 supervised classification, Landsat images were used to prepare LULC maps in the year 2001, 2005, 3762010,2015 , and 2017 of the study.

377 Water and forests were relatively well distinguished in land cover datasets and in Landsat 378 imagery. Water in the southeastern region was mainly distributed western portion of the Meghna 
379 River, southern part of the Bay of Bengal and inside lake water, while forests were in the 380 southeastern hilly areas of high altitudes.

381 When attempting to identify agricultural croplands, the results may vary considerably 382 depending on the date of image acquisition, because crops grow and are harvested according to 383 seasonal and annual phenological cycles. The study area is a sub-tropical region with three distinct 384 seasons and combination of low lying flat and undulating high topography (10 m to $200 \mathrm{~m}$ of sea 385 level). The pre-monsoon hot season from March through May receive little rainfall, excessive 386 rainfall and flooding in rainy monsoon season which starts from June through October, and a cool 387 dry winter season from November through February [31]. In sufficient rainfall and alluvial 388 floodplain areas as northern and western portion of the region, rice is cultivated in paddy fields 389 from December until the following July [32]. Rice is often intercropped with grain and cash crops, 390 beans, and vegetables. However, in other areas plants that do not require much water, such as corn, 391 peanuts, and tobacco, are cultivated even in dry season. Croplands were often leading to confusion 392 with grasslands. 

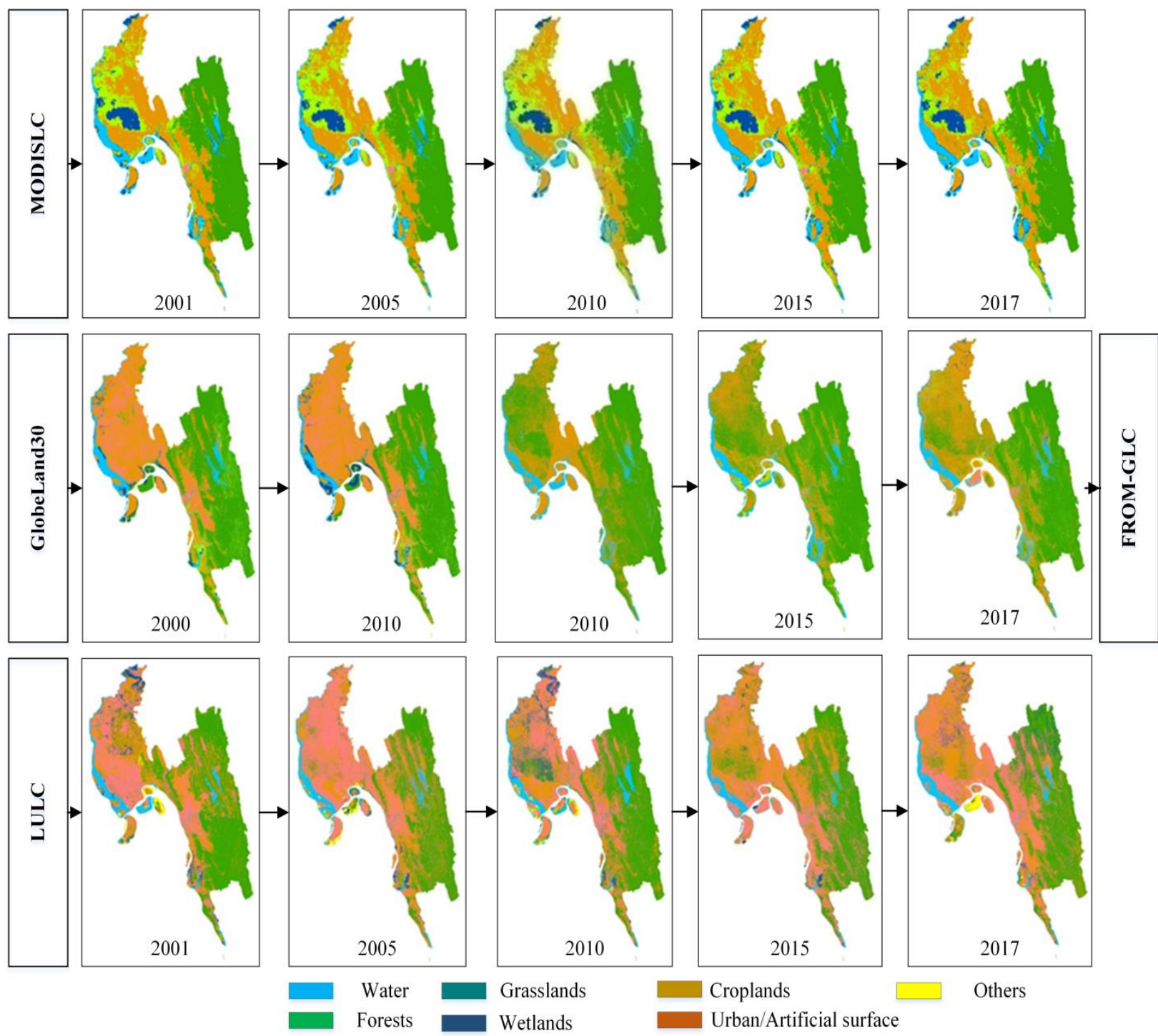

Wetlands

Urban/Artificial surface

Others

Fig. 6 Land use classification of the southeastern region of Bangladesh from the MODISLC, GlobeLand30, FROMGLC, and LULC of Landsat imaginary datasets.

396 Wetlands were the common feature here of low lying flat topography at the floodplain region

397 of northwestern areas and tidal floodplain lands of southern areas of the study. In seasonal

398 variation, those were converted to croplands or water bodies as well as salt and shrimp cultivating

399 nature. Therefore, the area of wetlands composition and distribution were identified high variation

400 in different land cover datasets were different. 
The MODISLC and the FROM-GLC datasets were presented the urban and built-up areas as

402 of city centers areas only, while the GlobeLand30 and LULC classes described as artificial surfaces

403 as well as rural and urban settlements, roads, and all other infrastructures in a broad category.

\subsection{Composition, Distribution and Changes of Major LULC Classes}

405 The study area is a predominantly agrarian region due to its fertile soil and favorable weather, 406 which is suitable for many varieties of crops in a year [50]. Currently, around 60\% of the land in 407 Bangladesh is available for cultivation. However, agricultural land has been lost due to rapid 408 urbanization, industrialization and soil salinization [51]. Suitability index mapping found that most 409 areas across the country have potential for agricultural activities, except the southeastern, 410 southwestern, and northeastern margins of the country [52]. However, LUCC research results (Fig.

411 7) suggest that in between 2001 to 2017, croplands, grasslands, and wetlands have decreased in 412 area, concurrent with the significant increases in water bodies, forest cover, and artificial surfaces 413 throughout the region. The LUCC results were mainly synthesized of the comprehensive 414 evaluations in four different land cover classes of the MODISLC, FROM-GLC, GlobeLand30, and 415 LULC classes of Landsat imaginary datasets.

416 Spatio-temporal studies revealed that in 2001, the total area of cropland was $31 \%$ of the study 417 area and in 2017 it has revealed 29.7\%. The study pointed out that croplands areas were 418 substantially decreased about $1.3 \%$ with a contraction rate of $0.1-0.8 \%$ per year $\left(\mathrm{R}^{2}=0.019\right)$ during 419 2001-2017 period of study. On the other hand, overall the urban and built-up areas as well as 420 artificial surfaces of the southeastern region of Bangladesh increased significantly between 2001 421 and 2017. In 2001, the built-up areas were listed as 11.8\%, which as increased to $13.8 \%$ in 2017 422 of the mutually distributed over the study area. Overall about $2 \%$ of the urban land cover areas 423 were increased with a rate of $1.2 \%\left(\mathrm{R}^{2}=0.347\right)$ per year during this period of study. 

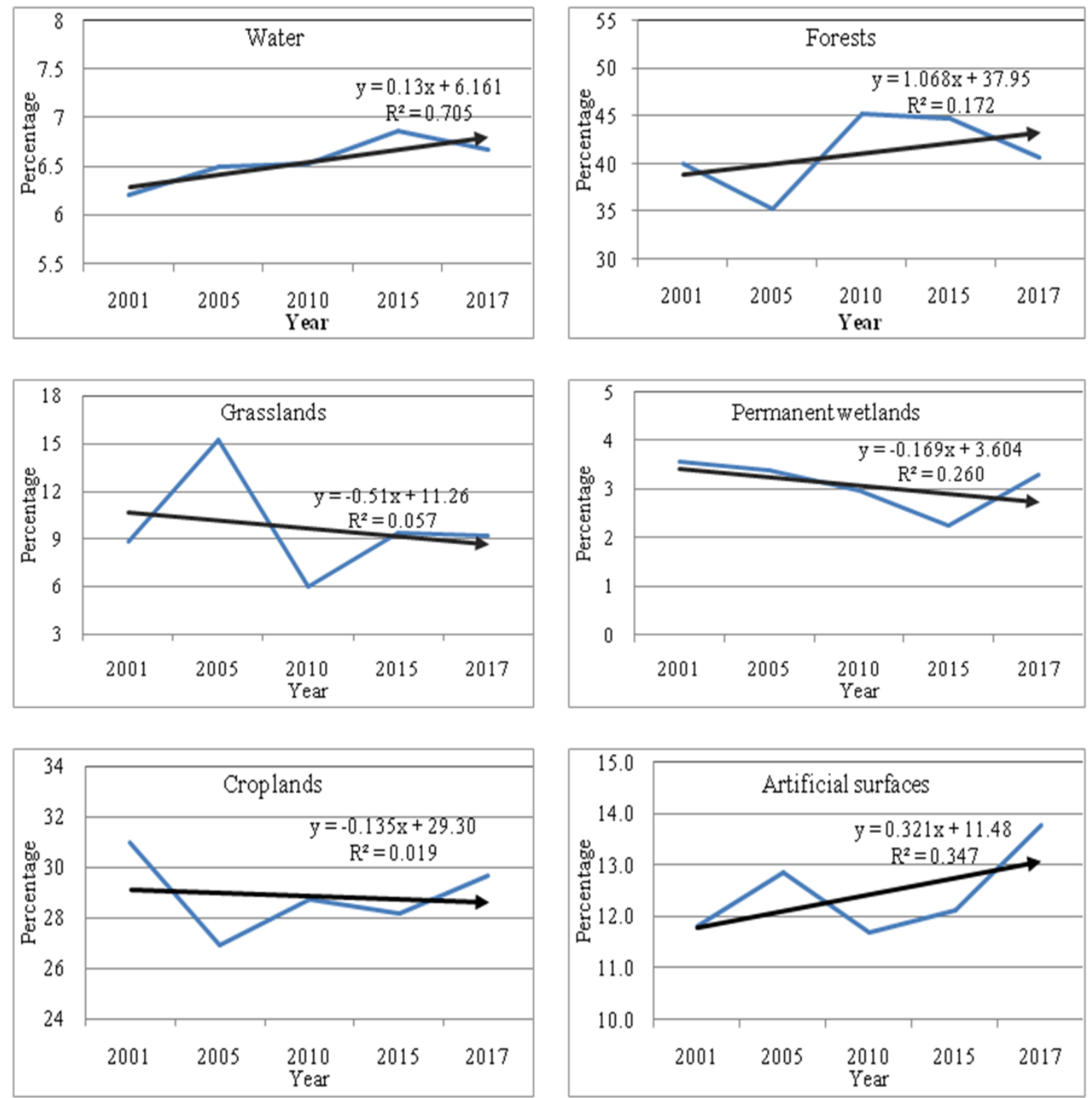

Fig. 7 The different LUCC status at the southeastern region of Bangladesh from different land cover products in average of the MODISLC (2001 to 2017), FROM-GLC (2010, 2015, 2017), GlobeLand30 (2000, 2010), and Landsat imaginary $(2001,2005,2010,2015,2017)$ datasets.

428 In the southeastern region of Bangladesh, the sources of water are primarily surface and ground

429 waters such as rivers and khals, lakes, beel, haor, char, and wetlands. Beel refers to low lands

430 mainly lying in the floodplains and deltaic region. Haor refers to the low-lying vast depression

431 areas that flooded during the monsoon and dried out in winter [53, 54]. The haor areas are mostly

432 located in the north-eastern part of the study area that plays significant roles in the livelihoods of 
433 surrounding communities as well maintenance of biodiversity [55]. The study area has around $43437.6 \%$ of land below 10 m elevation [41]. Therefore, during monsoon season; rainfall, flooding, 435 and surges have converted agricultural land to water bodies in the various low lands across the 436 active floodplain areas of the study. From 2001 to 2017 on an average, the total water bodies' area 437 increased from 6.2 to $6.7 \%$ across the study area by $0.3 \%$ annually. On the other hand, the total 438 areas of beel and haor as well as wetlands have slightly decreased. On the basis of the 439 comprehensive evaluations of four different land cover datasets in an average, the total area 440 decreased from 3.6 to $3.3 \%$, about $0.3 \%$ annually from 2001 to 2017.

441 Spatial analysis has shown that the total forest cover was increasing in area and quality. The 442 different land cover products have indicated that forest cover increased about $0.6 \%$ from 2001 to 443 2017. The substantial changes have identified that the tree cover in reserve forest as well as natural 444 forest is decreasing but tree outside of forest was increasing. Some other research also identified 445 that vegetation coverage at the southeastern region of Bangladesh was increased by 0.43 SINDVI 446 indexed value during 2001-2016 [35] and the total tree canopy cover increased 4.3\% during the 447 2000-2014 time interval [56]. However, there are noticeable inconsistencies in between the various 448 national level studies regarding forest change. The grasslands are primarily situated north eastern 449 part of the study area. However, the area has in decreasing trend considerably $0.1 \%$ per year from $450 \quad 2001$ to 2017.

451 The change matrixes for the different land cover products of the MODISLC (2001-2017), the 452 FROM-GLC (2010-2017), the GlobeLand30 (2000-2010) and LULC classes (2001-2017) were 453 produced by post-classification comparison from the classification results, which yield "from-to" 454 change information identifying where, and how much, change has occurred (Table 8). As seen in 455 the matrix table of different land cover datasets, $85.5 \%, 60.7 \%, 75.3 \%$, and $38.7 \%$ of land covers 
remained unchanged of the MODISLC, FROM-GLC, GlobeLand30, and LULC class distributions

457 between the years.

458 Since historical time period, the agricultural land has transforming to non-agricultural land use

459 at different spatio-temporal scales. Clearly, previous research has shown that agricultural land has

460 been primarily transformed into urban land in recent decades [31, 57, 58, 59]. According to the

461 transfer matrix table (Table 8), cropland area losses have been due to transformations to built-up

462 areas and tree plantation outside of forest cover areas. Different transformation of land areas in

463 cropland were seen in different land covers products. It was seen that 282.9 and 600 sq. km land

464 areas of croplands have decreased in GlobeLand30 (2000-2010), and LULC (2001-2017) class,

465 other than increased in MODISLC (2001-2017) and FROM-GLC (2010-2017) by 917.8 and 358.1

466 sq. km respectively.

467 Based on a comprehensive review of previous LULC studies, rapid population growth has

468 resulted in high urbanization across all over Bangladesh [36]. Spatial analysis indicates that the

469 built-up area expanded primarily by replacing agricultural land, water bodies and forest areas.

470 Chittagong city, located in the southeast, is the second largest city in Bangladesh has also a high

471 rate of population growth and urban expansion [60]. The transfer table here has identified the urban

472 and built-up areas were expanding mainly by aggregation of croplands and forests areas over the

473 period of study.

474 Table 8 Land cover transition matrix in the southeastern region of Bangladesh in different land cover products of 475 the MODISLC (2001-2017), FROM-GLC (2010-2017), GlobeLand30 (2000-2010), and LULC (2001-2017)

\begin{tabular}{|c|c|c|c|c|c|c|c|c|c|}
\hline \multirow{8}{*}{ 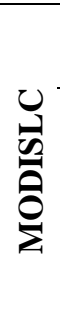 } & \multirow{2}{*}{\multicolumn{2}{|c|}{ Land Types }} & \multicolumn{7}{|c|}{2017} \\
\hline & & & $\mathrm{W}$ & $\mathrm{F}$ & GL & PW & $\mathrm{CL}$ & UB & Others \\
\hline & & Water & 2764.5 & 0 & 0.5 & 5.7 & 0 & 0 & 2.0 \\
\hline & & Forests & 0.3 & 13526.7 & 436.9 & 23.9 & 95.6 & 0 & 0.0 \\
\hline & $\bar{\theta}$ & Grasslands & 43.2 & 353.5 & 2770.9 & 336.1 & 1206.1 & 2.3 & 16.7 \\
\hline & ণิ & Permanent Wetland & 95.8 & 21.5 & 118.5 & 1799.9 & 25.5 & 0 & 29.7 \\
\hline & & Croplands & 58.1 & 503.5 & 1569.9 & 112.5 & 9565.1 & 0.5 & 2.0 \\
\hline & & Urban and Built-Up & 0 & 0 & 0 & 0 & 0 & 166.7 & 0 \\
\hline
\end{tabular}




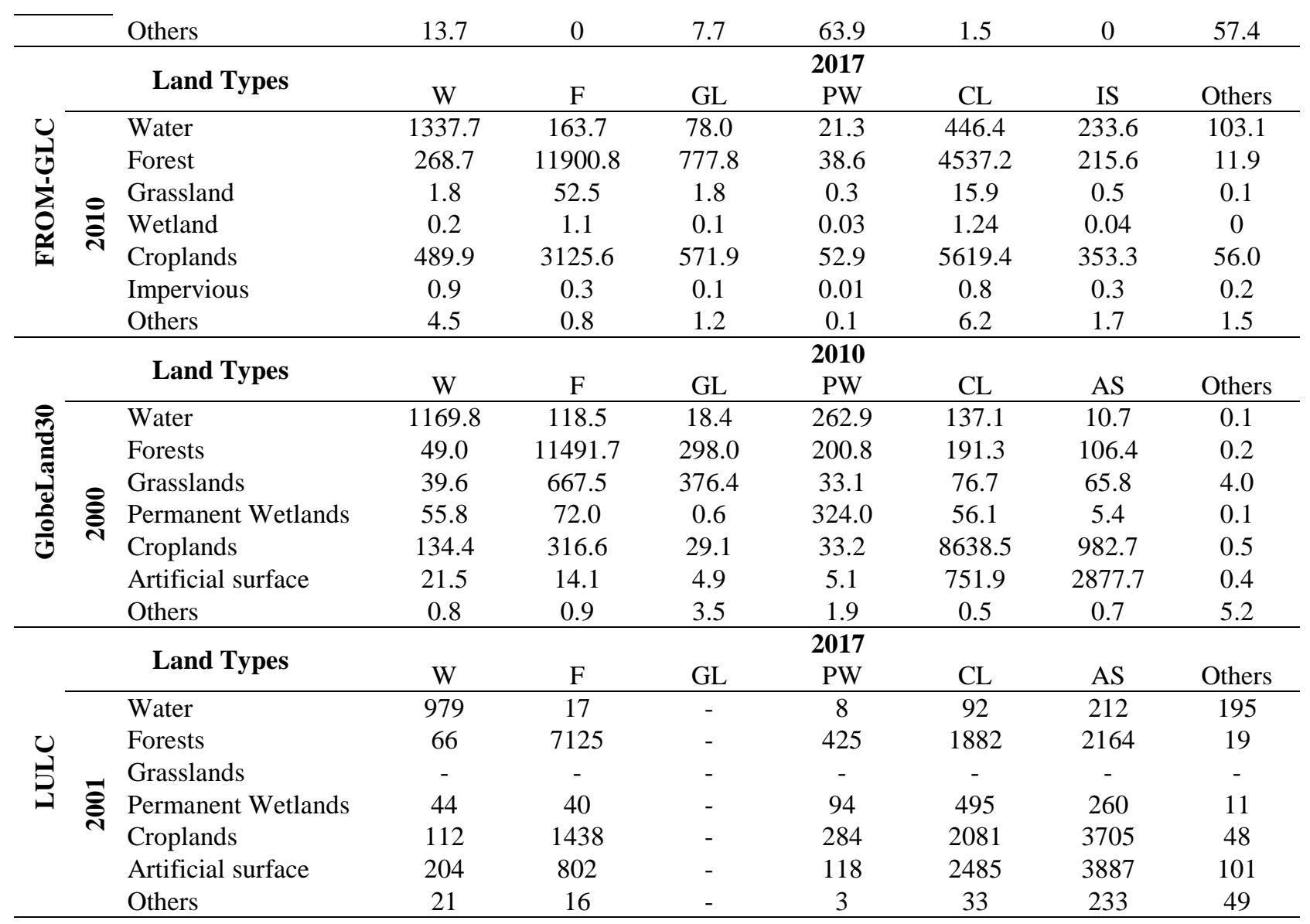

476 The study area has large sources of water resources from various channels and vast areas of

477 wetlands due to low lying topography. From the four different land cover in between 2001 and

478 2017, water bodies' areas were increased considerably while decreasing wetlands. Water areas

479 were mainly increased in transformation of wetlands in the northern part of the region, while

480 southern part has aggregated the croplands areas.

\section{Discussion}

\subsection{Pattern of Inconsistencies in Different Land Cover Mapping}

483 The comparisons of land cover products in previous studies have been made only at global [25,26],

484 continental [24], national [22], or provincial scales [27], since they focused on general patterns of

485 inconsistencies or indirect validation accuracy of the products, which is meaningful to large scale 
studies. To our knowledge, in small scale area as well in southeastern region of Bangladesh, this

487 is the first study to evaluate the amount of pair wise level of inconsistencies in different land cover 488 products (the MODISLC, FROM-GLC, GlobeLand30, and LULC of Landsat images) from 489 different view of spatial resolutions. It was found that the overall areal inconsistency and spatial 490 inconsistency of the FROM-GLC and GlobeLand30 is relatively small among the pairs of the four 491 products. While the pair of MODISLC and LULC was the highest overall areal and spatial 492 consistency in relative to others. The overall areal inconsistency other than spatial inconsistency 493 result is consistent with the conclusions in similar studies [20,22-24]. Both in overall areal and 494 spatial consistencies, the pair relation to the MODISLC were the highest inconsistencies. The 495 product of MODISLC was only land cover of $500 \mathrm{~m}$ spatial resolution other than $30 \mathrm{~m}$ of FROM496 GLC, GlobeLand30 and Landsat images. The second largest values of areal and spatial 497 inconsistencies were identified in pair related to LULC class of Landsat imaginary datasets. 498 However study in a small area may use the lower spatial resolution of land cover datasets as well 499 as FROM-GLC and GlobeLand30 land cover products.

500 The FROM-GLC had the smallest uncertainties due to the explicit relationships between 501 different classification levels. However, we quantitatively highlighted the uncertainties in 502 classification system conversion in this study. On the other hand in the classification system 503 conversion, IGBP-9 class was the lowest variation of uncertainties and inconsistencies, which were 504 recommended for later part of comprehensive evaluations of land use and land cover changes 505 analysis of the study. Although the study also recognized that a number of external factors (like 506 map projections, resolution unifications and mis-registration) are also the sources of the 507 uncertainties and discrepancies among the four products, which were not the focus of this paper. 
510 Since the independence of Bangladesh, the increasing population resulted the widely LUCC across

511 the country. The contractions of agricultural land to non-agricultural land resultant the various

512 consequences over the country. At the study area southeastern region of Bangladesh, on an average

513 of the four land cover products, overall about $0.5 \%$ croplands has decreased annually between

5142001 and 2017. The contraction rate has been slightly lower as decreased up to $1.45 \%$ annually

515 after 2000 in different divisions of the country [31,57].

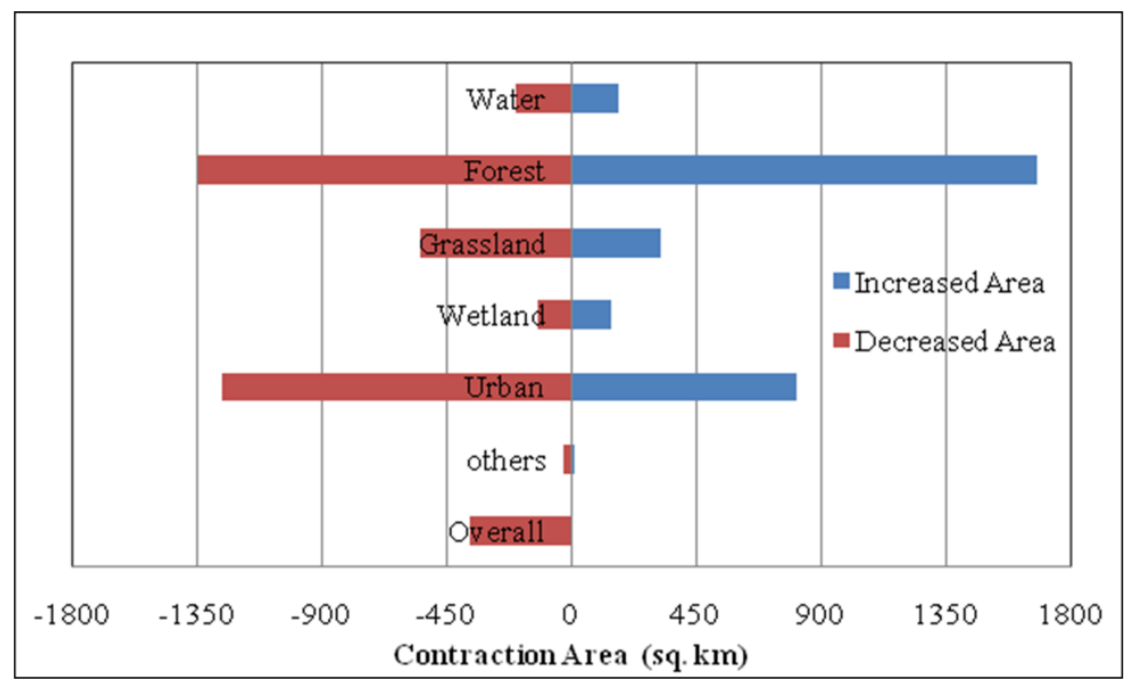

Fig. 8 The contraction of croplands area with all other LUCC classes at the southeastern region of Bangladesh from 2001 to 2017.

The contraction of croplands with major land cover classes between 2001 and 2017 has shown in Fig. 8. In an average of the four different land cover products, cropland was mainly decreased to forest as well as tree cover (1346 sq. km) and urban and built-up areas (1260 sq. km), while the land areas was increased by aggregation of forest (1677 sq. km) and artificial surface areas (809 sq. km).Overall about $59.6 \%$ of the croplands were unchanged during the period of study. With the time and introduced new farming technology, the study area adopted various ways to increase 
525 food production and minimize food insecurity. The start of agro-technological advancement

526 increased the production with crop intensity, which increased per capita income more than $130 \%$

527 and reduced the poverty level 50\% [61-62]. However, overall, the gross production of rice and

528 wheat increased significantly during the period between 1971/72 and 2010/11 from 10.46 to 35.3

529 million metric tons [61-63]. On the other hand, in 2005, Bangladesh's net AFOLU emissions were

53061.3 million $\mathrm{tCO}_{2} \mathrm{e}$, accounting for over $52 \%$ of the total net national emissions [64]. Agriculture

531 emitted 43.1 million tCO2e or about $35 \%$ of all emissions and $66 \%$ of AFOLU emissions, while

532 LULUCF constituted the remaining 34\% of AFOLU emissions with a net emission of 18.2 million

$533 \mathrm{tCO}_{2} \mathrm{e}$. The three most important emission sources in the agriculture sector were manure

534 management (representing $41 \%$ of agricultural emissions), enteric fermentation (24\%) and rice

535 cultivation (18\%) [65]. However the country requires of 23.64 million of metric tons (MMT) rice

536 and wheat for the total population [63]. Still, $40 \%$ of the rural populations live with a landless

537 status [22]. Furthermore, around $60 \%$ of farmers are functionally landless with about $62 \%$ of

538 farming households having less than 0.4 ha of farmland [66]. Therefore, food production is not

539 enough for all household. Due to decline in agriculture land, the overall production declined and

540 the problem of food insecurity is becoming more intense and they have to import food from 541 neighboring countries.

\section{$542 \quad$ 4.2.2 The effects of urban land development}

543 Rapid population growth is a major component of urban land development, historically, those 544 growth have been increasing significantly over the southeastern region of Bangladesh. Multiple 545 driving factors are responsible for the LUCC and artificial surface expansion [67]. Since 1990s, 546 the study area's population has grown rapidly by 20.5 to 28.4 million in between 1991 and 2011

547 [68]. The high rate of economic and population growth, massive infrastructure development, and 
548 impact of climate change have been major causes of rapid LUCC across the area [69]. The study

549 on LUCC of different land cover products has identified the urban and a built-up as well as

550 artificial surface at study area was increased mainly by accretion of croplands and forest

551 degradation (Fig. 9). From 2001 to 2017, about 1260 sq. km and 622 sq. km of croplands and

552 forest cover respectively have converted to urban and built-up areas. On the other hand, artificial

553 surface was converted to croplands and tree cover as well of 809 and 204 sq. km respectively

554 during this period. Overall about 1017 sq. km of urban and built-up areas was increased between

5552001 and 2017 period of study with an annual rate of 1.32\%.However, Hasan et al. (2013) [31]

556 found that the urban area increased 401 sq. km during 2000-2010 and Reddy et al. (2016) [70]

557 found that settlement area had increased 1643 sq. km (1.1\%) in 2000-2014, which were in agreed 558 with the results.

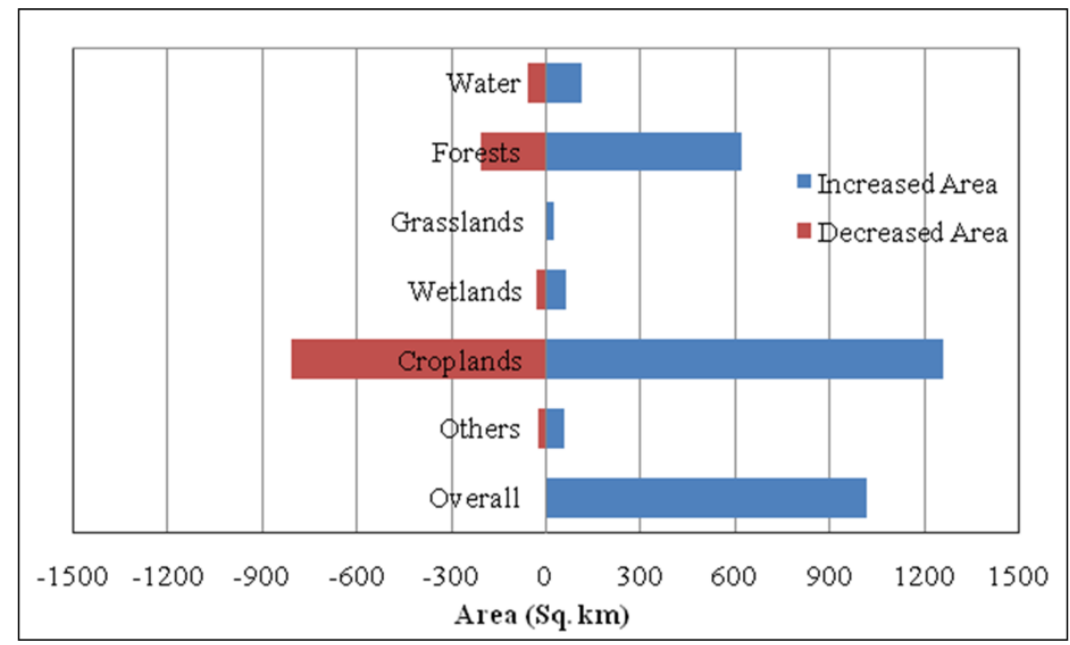

560 Fig. 9 The impacts of urban and built-up areas by major land cover classes of the study area from 2001 to 2017 in combination of four different land cover products

Approximately one-fourth of the national population lives in urban area [68] and increasing

563 urban population growth has resulted the urban expansion speedily, mostly in the city areas. As

564 result, infrastructure development with unplanned urbanization processes encroached on 565 agricultural land, forestland, low-lying areas, and water bodies, resulting in the transformation 
566 from vegetation cover to concrete built-up areas. These types of changes are incorporated to

567 vulnerable capital city as well other big cities from natural disasters and LUCC issues. One of the

568 obvious impacts of urban growth at the cost of agricultural land is the increasing problem of food

569 security. Similarly, the conservation of other land uses such as forest and water bodies has several

570 environmental and socio-economic consequences.

\subsubsection{The effects of forest cover and water bodies changes}

572 With the combination of hilly areas (62.4\%) and low elevation deltaic floodplain (37.6\%), the

573 southeastern region of Bangladesh has a tropical monsoon climate characterized by heavy seasonal

574 rainfall, high temperatures and high humidity [41]. Forest cover is mostly distributed in south-east

575 part of the study area of hilly region (Fig. 6). The impacts of forest cover and water bodies in the

576 southeastern region of Bangladesh in an average of the four different land cover of the MODISLC,

577 FROM-GLC, GlobeLand30, and LULC classes has described in Fig. 10. In between 2001 and

578 2017, forest cover at the study area was mainly affected by croplands as of 1346 sq. km was

579 aggregated. Forest cover was also found changed to grasslands and build-up areas. Overall the

580 forest cover at the study area has increased by 1022 sq. $\mathrm{km}$ as $0.4 \%$ annually during this period.

581 However, Patopov et. al. (2017) [56] was also identified; tree cover outside of forest was increased

582 as of overall $4.3 \%$ total canopy cover increased over the country during 2000-2014 period and

583 Islam et. al. (2018) [35] found 0.43 indexed value of increased SINDVI at the study during 2001-

584 2016, which support the study results. Although overall tree cover is increasing, spatial distribution

585 of forest cover showed that tree canopy cover in reserve forest at the south-east region of the study

586 area was decreased, while increased plantations in settlement and cropland areas. However, due to

587 the high demand for wood and wood products, the overall forest cover status is increasing rate

588 after 2000 which also shows very less per capita forest land in the world. According to FAO 
589 (2010b) [71], the average per capita forest land is 0.60 ha globally; however, in recent decades,

590 Bangladesh has only reached 0.12 ha per capita forest land. The forest department has implemented

591 several massive programs and projects to regenerate and reforest after the devastating cyclone of

592 1960.The impacts of these programs have been observed since 2000. Furthermore, illicit felling of

593 forest cover also improved after 2000. Bangladesh is considered the world's most vulnerable

594 country to the negative impacts of climate change, facing particularly high risks from tropical

595 cyclones and floods specially the study area southeastern region of Bangladesh. In response, the

596 country has prioritized adaptation and has invested over US\$ 10 billion of its own resources to

597 increase its climate resilience [72]. Nonetheless, Bangladesh has also implemented mitigation

598 activities, including in the AFOLU sector. Current and planned AFOLU mitigation activities

599 include afforestation/ reforestation, REDD+, climate resilient agriculture, lowering methane

600 emissions in agricultural production, crop diversification, fertilizer management and improved

601 livestock management. The country has several NAMAs under development in the industry and

602 waste sectors and is exploring potential in other sectors [72].

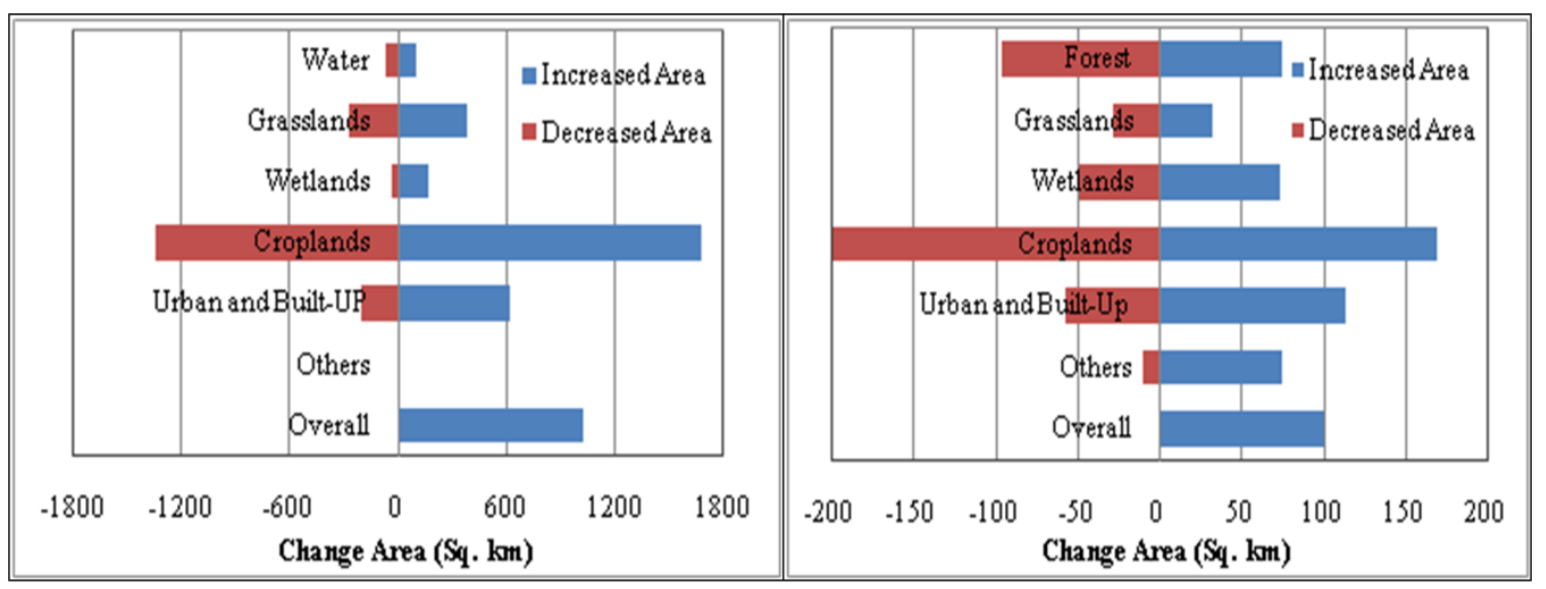

603

(a)

(b)

604 Fig. 10 The impacts of (a) forest covers and (b) water bodies in major LUCC classes in four different lands cover 605 products from 2001 to 2017 
Due to foothills of the Himalayas and low lying riverine the country shares 57 trans-boundary

607 rivers. The rivers play the important role for agriculture as the well high risk of floods and river

608 erosion within the study area. In an average of four different land cover products, overall the water

609 areas in the study has increased 100 sq. km. Water area was mainly increasing by logged and

610 flooded of cropland and built-up areas. In recent decades, due to the high rate of population growth

611 and urbanization process, the wetlands surrounding the built-up areas have seriously degraded

612 [58].This wetlands change and unplanned urbanization as well as development have made the

613 drainage system in the urban areas vulnerable to water logging problems and their consequences.

614 Moreover, due to high profit from shrimp and salt cultivation, water bodies at the southern coastal

615 areas have increased up to $500 \%$ after 1980 s in the southern regions [51]. On the one hand the

616 shrimp farming improved the local livelihood; but on the other hand, intensive shrimp farming has

617 impacted coastal land use with creating saline water intrusions, which may destruction the

618 wetlands as well as water bodies and rice ecosystems as well decrease of rice production.

\section{Conclusion}

620 Bangladesh has undergone rapid LUCC due to speedy population growth and urbanization that

621 resulted sharp contractions in agricultural land. Using the common classification systems, this

622 study tried to assess the spatial and areal inconsistencies in the four most recent multi-resource

623 land cover products and based on this inconsistencies, a synthesis of study was triggered out on

624 land use and land cover dynamics during 2001-2017 in the southeastern region of Bangladesh. The

625 four recent land cover products of the MODISLC, FROM-GLC, GlobeLand30, and LULC class

626 of Landsat imaginary datasets were used in different time frame on the basis of their data sources

627 availabilities. 
The overall areal and spatial inconsistencies in the widely used classification system

629 conversion decreased with the decreasing of the thematic detail in the classification scheme as

630 from IGBP-17 to TC. This indicates that the assessment of areal and spatial inconsistencies is

631 primarily influenced by the thematic detail of the common classification systems. In compared to

632 different pair of land cover datasets, the pairs related MODISLC land cover product were the

633 highest areal and spatial inconsistencies while the FROM-GLC and GlobeLand30 was the smallest

634 one. However, in referenced datasets, spatial resolution might be one of the prime concerns of land

635 cover data validation; the lower the spatial resolution is the better of land cover indication. The

636 foregoing pair-wise comparative analyses provide insight for both data produces and users. For

637 data producers, the identified areas of lower inconsistencies may serve as a reference data for

638 training areas selection. Likewise, areas of higher inconsistencies may receive special attention in

639 future land cover characterization and mapping. Users also will have an opportunity to examine

640 the similarities and differences in their area of interest, and make informed decisions based on their

641 thematic applications. Learning from past experience and building on the existing infrastructure

642 (e.g., regional network), the consistency and accuracy of global land cover data are expected to

643 improve in the future.

644 The four different land cover products used in land use cover changes in the study were in

645 different classification schemes. This study was reclassified them into a common classification

646 system and were discussed the LUCC status by their comprehensive changing results. For land use

647 classification, IGBP-9 (as identified lower variations of inconsistencies) suggests adopting nine

648 land use categories: water; forests; shrublands; grasslands; wetland; croplands; urban and built-up;

649 snow and ice; and others. All land cover products and Landsat satellite images of the land areas of

650 southeastern region of Bangladesh was classified/reclassified in accordance with this suggested 
651 land use categories. As of 2017, forests and croplands were the principle dominates the land cover 652 of this region, comprising $40.2 \%, 50 \%, 31.7 \%$, and $42.6 \%$ of forests and $30.4 \%, 34.8 \%, 23.8 \%$, 653 and $32.2 \%$ of croplands in the four different land covers of MODISLC, FROM-GLC, LULC, and

654 GlobeLand30 datasets respectively. Based on the systematic assessment in an average of the four 655 different land cover products in the southeastern region of Bangladesh, this study concluded that 656 the land areas of water, forests, and artificial surfaces were increased in different spatial and 657 temporal dynamics, while croplands, grasslands, and wetland were decreased. The major effects 658 of LUCC dynamism were mainly circulated in the changing pattern of croplands, forests, and 659 artificial surfaces of the study area. However, the historical spatio-temporal LUCC results are 660 inconsistent between studies. Although the research was focuses on uncertainty in the land cover 661 data, it would be useful to highlight the contribution of the AFLOU sector in Bangladesh to the 662 GHG emissions and would be further helpful to understand the consequence of climate change 663 mitigation. Further LUCC study is needed to examine the historical data with new methods, tools, 664 and data resources in the context of environmental change at the national and regional scale. The 665 trans-boundary river basin is one of the most important water resources in South Asian countries 666 for agriculture and human needs, yet few studies have addressed this area. Further LUCC study is 667 needed to improve accuracy, eliminate uncertainties and discrepancies in the spatio-temporal 668 changes. 
670 S.I. and M.M. conceived and designed the experiments and research; S.I. and M.Z. performed the experiments

671 and analyzed the data; and S.I., H.Y. and M.M. jointly revised the paper.

\section{Conflicts of Interest:}

673 The authors declare no conflict of interest.

\section{Acknowledgements:}

675 This work was jointly supported by the NSFC (National Natural Science Foundation of China) project (grant 676 number: 41771453, 41830648), the Chongqing R\&D Project of the high technology and major industries (grant 677 number: [2017] 1231). In this study, multi-resource land cover datasets were downloaded from different data 678 centers. The data include MODISLC, GlobeLand30, FROM-GLC, and Landsat images obtained from LP 679 DAAC, National Geomatics Center of China (NGCC), Tsinghua University of China, and USGS respectively. 680 The authors express their gratitude for the data sharing of above datasets.

\section{References}

1. J. F. Yin, X. W. Zhan, Y. F. Zheng, C. R. Hain, M. Ek, J. Wen,; L. Fang, and J. C. Liu, "Improving

684 Noah land surface model performance using near real time surface albedo and green vegetation

685 fraction,” Agric. For. Meteorol. 218, 171-183 (2016).

686 2. X. H. Wen, S. H. Lu, and J. M. Jin, "Integrating remote sensing data with WRF for improved

687 simulations of oasis effects on local weather processes over an arid region in northwestern China," $J$.

$688 \quad$ Hydro meteorol., 13, 573-587 (2012).

689 3. GCOS, The second report on the adequacy of the Global Observing System for Climate Support of

690 the UNFCC, GCOS-82. Secretariat of the World Meteorological Organization: Geneva, Switzerland, $69174 \mathrm{pp}(2003)$.

692 4. R. A. Houghton, J. I. House, J. Pongratz, G. R. van der Werf, R. S. DeFries, M. C. Hansen, C.

693 LeQuere, and N. Ramankutty, "Carbon emissions from land use and land cover change,"

694 Biogeosciences 9, 5125-5142 (2012). 
695 5. S. W. Running, D. D. Baldocchi, D. P. Turner, S. T. Gower, P. S. Bakwin, and K. A. Hibbard, "A 696 global terrestrial monitoring network integrating tower fluxes, flask sampling, ecosystem modeling 697 and EOS satellite data," Remote Sens. Environ. 70, 108-127 (1999).

698 6. M. Herold, J. S. Latham, A. DiGregorio, and C. C. Schmullius, "Evolving standards inland cover 699 characterization," J. Land Use Sci. 1 (2-4), 157-168 (2006).

700 7. M. E. Andrew, M. A. Wulder, and T. A. Nelson, "Potential contributions of remote sensing to 701 ecosystem service assessments," Prog. Phys. Geogr. 38 (3), 328-353 (2014).

702 8. J. J. Feddema, K. W. Oleson, G. B. Bonan, L. O. Mearns, L. E. Buja, G. A. Meehl, and W. M. 703 Washington, “The importance of land-cover change in simulating future climates," Science, 310, $704 \quad 1674-1678(2005)$.

705 9. C. Zhang, C. Li, X. Chen, G. Luo, L. Li, X. Li, Y. Yan, and H. Shao, “A spatial-explicit dynamic 706 vegetation model that couples carbon, water, and nitrogen processes for arid and semiarid 707 ecosystems, " J. Arid Land 5, 102-117 (2013).

708 10. T. R. Loveland, B.C. Reed, J. F. Brown, D. O. Ohlen, Z. Zhu, L. Yang, and J. W. Merchant, 709 "Development of a global land cover characteristics database and IGBP DISCover from $1 \mathrm{~km}$ 710 AVHRR data," Int. J. Remote Sens. 21, 1303-1330 (2000).

711 11. M. Hansen, and B. A. Reed, "A comparison of the IGBP discover and university of Maryland $1 \mathrm{~km}$ 712 global land cover products,” Int. J. Remote Sens. 21, 1365-1373 (2000).

713 12. H. Xie, X. Tong, and W. Meng et al. "A multilevel stratified spatial sampling approach for the quality 714 assessment of remote-sensing-derived products," IEEE Journal of Selected Topics in Applied Earth 715 Observations and Remote Sensing, 8(10): 4699-4713 (2015) [DOI: 10.1109/JSTARS.2015.2437371].

716 13. S. Faroux, A. T. KaptuéTchuenté, J. L. Roujean, V. Masson, E. Martin, AND P. Le Moigne,

717 "ECOCLIMAP-II/ Europe: A twofold database of ecosystems and surface parameters at $1 \mathrm{~km}$ 718 resolution based on satellite information for use in land surface, meteorological and climate models," 719 Geosci. Model Dev., 6, 563-582 (2013). 
14. M. A. Friedl, D. Sulla-Menashe, B. Tan, A. Schneider, N. Ramankutty, A. Sibley, and X. Huang,

721 "MODIS Collection 5 global land cover: Algorithm refinements and characterization of new

722 datasets," Remote Sens. Environ., 114, 168-182 (2010).

723 15. P. Gong, J. Wang, L. Yu, Y. Zhao, Y. Zhao, L. Liang, Z. Niu, X. Huang, H. Fu, S. Liu et al. "Finer

724 resolution observation and monitoring of global land cover: First mapping results with Landsat TM

725 and ETM+ data," Int. J. Remote Sens., 34, 2607-2654 (2013).

726 16. J. L. Champeaux, V. Masson, and F. Chauvin, "Ecoclimap: A global database of land surface

727 parameters at 1 km resolution,” Meteorol. Appl., 12, 29-32 (2005), ISPRS Int. J. Geo-Inf., 6, 11217

728 of $17(2017)$.

729 17. M. Friedl, and D. Sulla-Menashe, MCD12Q1 MODIS/Terra+Aqua Land Cover Type Yearly L3

730 Global 500m SIN Grid V006 [Data set], NASA EOSDIS Land Processes DAAC,

731 (2015), [doi:10.5067/MODIS/MCD12Q1.006]

732 18. J. Chen, J. Chen, A. Liao, X. Cao, L. Chen, X. Chen, C. He, G. Han, S. Peng, M. Lu et al. "Global

733 land cover mapping at 30 m resolution: A POK-based operational approach," ISPRS J. Photogramm.

$734 \quad$ Remote Sens., 103, 7-27 (2015).

735 19. J. J. Arsanjani, A. Tayyebi, and E. Vaz, "GlobeLand30 as an alternative fine-scale global land cover

736 map: Challenges, possibilities, and implications for developing countries," Habitat Int., 55, 25-

737 31(2016).

738 20. C. Giri, B. Pengra, J. Long, and T. R. Loveland, "Next generation of global land cover

739 characterization, mapping, and monitoring," Int. J. Appl. Earth Obs. Geoinf., 25, 30-37(2013).

740 21. A. H. Strahler, L. Boschetti, G.M. Foody, M. A. Friedl, M. C. Hansen, M. Herold, P. Mayaux, J. T.

741 Morisette, S. V. Stehman, and C. E. Woodcock, "Global Land Cover Validation: Recommendations

742 for Evaluation and Accuracy Assessment of Global Land Cover Maps," European Communities:

743 Luxembourg City, Luxembourg, (2006). 
22. Y. Bai, M. Feng, H. Jiang, J. Wang, Y. Zhu, and Y. Liu, “Assessing consistency of five global land cover data sets in China," Remote Sens., 6, 8739-8759 (2014).

23. Y. Ran, X. Li, and L. Lu, "Evaluation of four remote sensing based land cover products over china," Int. J. Remote Sens., 31, 391-401(2010).

24. A. T. KaptuéTchuenté, J. L. Roujean, and S. M. de Jong, “Comparison and relative quality assessment of the GLC2000, GLOBCOVER, MODIS and ECOCLIMAP land cover data sets at the African continental scale," Int. J. Appl. Earth Observ. Geoinf., 13, 207-219 (2011).

25. I. McCallum, M. Obersteiner, S. Nilsson, and A. Shvidenko, “A spatial comparison of four satellite derived $1 \mathrm{~km}$ global land cover datasets," Int. J. Appl. Earth Obs. Geoinf., 8, 246-255 (2006).

26. R. Latifovic, and I. Olthof, “Accuracy assessment using sub-pixel fractional error matrices of global 754 land cover products derived from satellite data," Remote Sens. Environ., 90, 153-165 (2004).

755 27. X. Ye, J. Zhao, L. Huang, D. Zhang, and Q. Hong, “A comparison of four global land cover maps on a provincial scale based on China's $30 \mathrm{~m}$ globeland30," In Proceedings of the International Conference on Geo-Informatics in Resource Management and Sustainable Ecosystems, Hong Kong,

28. S. Fritz and L. See, "Identifying and quantifying uncertainty and spatial disagreement in the comparison of global land cover for different applications," Glob. Chang. Biol., 14, 1057-1075 (2008).

29. E. Lambin, B. Turner, H. Geist, S. Agbola, A. Angelsen, J. Bruce, O. Coomes, R. Dirzo, G. Fischer, C. Folke et al. "The causes of land-use and land-cover change, moving beyond the myths," Glob. Environ.Chang., 11, 261-269 (2001). synthesis of information on rapid land-cover change for the period 1981-2000," BioScience, 55, 115$124(2005)$. 
31. Food and Agriculture Organization of the United Nations Regional Office for Asia and the Pacific, FAO, Statistical Yearbook 2014: Asia and the Pacific Food and Agriculture, Food and Agriculture Organization of the United Nations Regional Office for Asia and the Pacific: Bangkok, Thailand, (2014).

772 32. M. Hasan, M. Hossain, M. Bari, and M. Islam, "Agricultural Land Availability in Bangladesh, SRDI, 773 Ministry of Agriculture, Dhaka, Bangladesh, p. 42. ISBN 978-984-33-6141-7 (2013).

774 33. Population Reference Bureau, World Population Data Sheet with a Special Focus on Human Needs 775 and Sustainable Resources, Population Reference Bureau: Washington, DC, USA, (2016).

776 34. S. S. Hasan, X. Deng, Z. Li, and D. Chen, "Projections of Future Land Use in Bangladesh under the 777 Background of Baseline, Ecological Protection and Economic Development," Sustainability, 9, 505 778 (2017).

779 35. S. Islam and M. Ma, "Geospatial Monitoring of Land Surface Temperature Effects on Vegetation 780 Dynamics in the Southeastern Region of Bangladesh from 2001 to 2016," ISPRS Int. J. Geo-Inf., 7, 781486 (2018) [doi:10.3390/ijgi7120486].

782 36. R. Rai, Y. Zhang, B. Paudel, S. Li, and N. R. Khanal, "A Synthesis of Studies on Land Use and Land 783 Cover Dynamics during 1930-2015 in Bangladesh,” Sustainability, 9, 1866 (2017).

784 37. D. M. Olson, “Terrestrial Ecoregions of the World: A new map of life on earth,” Bioscience, 51, 933$785938(2001)$

786 38. N. Myers, R. A. Mittermeier, C. G. Mittermeier, G. A. B. da Fonseca, and J. Kent, "Biodiversity 787 hotspots for conservation priorities," Nature, 403, 853-858 (2000).

788 39. Bangladesh National Portal, Chittagong Division, Cabinet Division, Government of the People's 789 Republic of Bangladesh. Available online: http://www.chittagongdiv.gov.bd/site/page/98079ea0$790 \quad \underline{2144-11 e 7-8 f 57-286 e d 488 c 766}$ (accessed on 11 May 2018).

791 40. S. Miah, Banglapedia: National Encyclopedia of Bangladesh, 2nd ed., Islam, S., Ahmed, A.J., Eds.; 792 Asiatic Society of Bangladesh: Dhaka, Bangladesh (2012). 
793 41. BBS, Population Census 2011, Bangladesh Bureau of Statistics, Government People’s Republic of 794 Bangladesh, Dhaka, Bangladesh (2011).

795 42. A. Dewan and R. Corner, "Dhaka Megacity: Geospatial Perspectives on Urbanisation, Environment 796 and Health,” Springer, New York, NY, USA (2014).

797 43. J. Chen, X. Cao, S. Peng, and H. Ren, “Analysis and Applications of GlobeLand30: A

798 Review," ISPRS Int. J. Geo-Inf., 6, 230 (2017).

799 44. NASA’s Earth Observing System Data and Information System, Available online:

800 https://search.earthdata.nasa.gov/search?q=MCD12Q1\&ok=MCD12Q1 (assessed on 12 January

$801 \quad 2019)$

802 45. National Geomatics Center of China, Available online:

803 http://www.globallandcover.com/GLC30Download/download.aspx (assessed on 7 December 2019)

804 46. Center for Earth System Science, Tsinghua University, Available online:

805 http://data.ess.tsinghua.edu.cn/ (assessed on 15 January 2019)

806 47. USGS Global Visualization Viewer (GloVis). Available online: https://glovis.usgs.gov/ (assessed on

$807 \quad 21$ January 2019)

808 48. M. Zhang, M. Ma, P. De Maeyer, and A. Kurban, "Uncertainties in Classification System Conversion

809 and an Analysis of Inconsistencies in Global Land Cover Products," ISPRS Int. J. Geo-Inf., 6, 112

$810 \quad$ (2017).

811 49. J. R. Jensen, Introductory digital image processing: a remote sensing perspective, 3rd ed., Bergen

$812 \quad$ (NJ): Pearson Prentice Hall (2005).

813 50. Bangladesh Bureau of Statistics, Yearbook of Agricultural Statistics-2015, Bangladesh Bureau of

814 Statistics (BBS), Statistics and Informatics Division (SID): Dhaka, Bangladesh, (2016).

815 51. G. M. Islam, A. K. Islam, A. A. Shopan, M. M. Rahman, A. N. Lazar, and A. Mukhopadhyay,

816 "Implications of agricultural land use change to ecosystem services in the Ganges delta," J. Environ.

817 Manag., 161, 443-452 (2015). 
52. M. Malek, M. Hossain, R. Saha, and F. Gatzweiler, "Mapping Marginality Hotspots and Agricultural

819 Potentials in Bangladesh,” University of Bonn, Bonn, Germany, pp. 1-30 (2013).

820 53. A. Alam, M. Chowdhury, and I. Sobhan, Biodiversity of Tanguar Haor: A Ramsar Site of

821 Bangladesh, Wildlife: International Union for Conservation of Nature, Volume I, Dhaka,

$822 \quad$ Bangladesh, pp. 1-234 (2012).

823 54. S. Khondoker, M. L. Hossain, and K. A. H. Moni, "Wetland management in Bangladesh: A study on

824 BeelBakar," Agric. For. Fish., 3, 320-328 (2014).

825 55. T. Majumder, S. K. Mazumder, M. M. Monwar, and L. Basak, "Towards climate change resilient of

826 Hail Haor, Sylhet: Reviewing the role of the co-management approach,” IOSR J. Agric. Vet. Sci., 5,

$827 \quad 59-66(2013)$.

828 56. P. Potapov, "Comprehensive monitoring of Bangladesh tree cover inside and outside of forests,

829 2000-2014” Environ. Res. Lett., 12, 104015 (2017).

830 57. M. A. Quasem, "Conversion of agricultural land to non-agricultural uses in Bangladesh: Extent and

831 determinants," Bangladesh Dev. Stud., 34, 59-85 (2011).

832 58. M. Uddin, M. Anwar, M. Rahman, and M. Mobin, “An investigation on the pattern of land use

833 change in Dhaka city using remote sensing and GIS application,” J. Environ. Sci. Nat. Resour., 7,

$834 \quad 105-109$ (2014).

835 59. A. Ahmed, and S. H. Hussain, "Changing Urban Land use and Agricultural Land Transformation: A

836 Case Study of Narayanganj City,” ASA Univ. Rev., 6, 237-284 (2012).

837 60. S. Roy, K. Farzana, M. Papia, and M. Hasan, "Monitoring and Prediction of Land Use/Land Cover

838 Change using the Integration of Markov Chain Model and Cellular Automation in the Southeastern

839 Tertiary Hilly Area of Bangladesh,” Int. J. Sci. Basic Appl. Res., 24, 125-148 (2015).

840 61. Food and Agriculture Organization of the United Nations FAO, Bangladesh Food Security Brief;

841 World Food Programme, Vulnerability Analysis and Mapping Unit WFP, Dhaka, Bangladesh,

$842 \quad$ (2005). 
62. M. Begum, and L. D’Haese, “Supply and demand situations for major crops and food items in

844 Bangladesh,” J. Bangladesh Agric. Univ., 8, 91-102 (2010).

845 63. M. Kashem, and M. A. Faroque, "Country Scenarios of Food Security and Governance in

846 Bangladesh,” J. Sci. Found, 9, 41-50 (2011).

847 64. MOEF (2012), “Government of the People's Democratic Republic of Bangladesh. Second National

848 Communication to the UNFCCC," Ministry of Environment and Forests.

849 http://unfccc.int/resource/docs/natc/bgdnc2.pdf.

850 65. A. Zeleke, "Role of Agriculture, Forestry and Other Land Use Mitigation in INDCs and National

851 Policy in Asia," LEDS, Agriculture, Forestry and Other Land Use (AFOLU) Working Group, (2016).

852 66. R. Magnani, L. Oot, K. Sethuraman, G. Kabir, and S. Rahman, "USAID Office of Food for Peace

853 Food Security Country Framework for Bangladesh (FY 2015-2019),” Food and Nutrition Technical

854 Assistance III Project, Washington, DC, USA, pp. 1-69 (2015).

855 67. B. Rimal, L. Zhang, H. Keshtkar, N. Wang, and Y. Lin, "Monitoring and Modeling of Spatiotemporal

856 Urban Expansion and Land-Use/Land-Cover Change Using Integrated Markov Chain Cellular

857 Automata Model,” ISPRS Int. J. Geo-Inf., 6, 288 (2017).

858 68. Bangladesh Bureau of Statistics, Population and Housing Census-2011; Bangladesh Bureau of

859 Statistics (BBS), Ministry of Planning, Statistics and Informatics Division (SID), Dhaka, Bangladesh,

$860 \quad$ pp. $1-640(2014)$.

861 69. K. Uddin, D. Gurung, "Land cover change in Bangladesh- a knowledge based classification

862 approach," In Proceedings of the 10th International Symposium on High Mountain Remote Sensing

863 Cartography ICIMOD, Kathmandu, Nepal, 8-11 September, pp. 41-46 (2008).

864 70. C. S. Reddy, S. V. Pasha, C. S. Jha, P. G. Diwakar, V. K. Dadhwal, "Development of national 865 database on long-term deforestation (1930-2014) in Bangladesh," Glob. Planet. Chang, 139, 173-

$866182(2016)$ 
867 71. Food and Agriculture Organization of the United Nations (FAO), Global Forest Resources

868 Assessment 2010 Country Reports, Bangladesh, Forestry Department, Food and Agriculture

869 Organization of the United Nations: Rome, Italy (2010).

870 72. Anita, Wahida Musara. Status of Climate Finance and NAMA in Bangladesh. Ministry of

871 Environment and Forest. Regional Workshop on NAMA.

872 http://unfccc.int/files/focus/mitigation/application/pdf/bangladesh regional workshop on nama.pptx

$873 \quad$ - revised.pdf.

874 73. MOEF (2009), Government of the People's Republic of Bangladesh. Bangladesh Climate Change

875 Strategy and Action Plan (BCCSAP) for 2009- 2018. Ministry of Environment and Forests.

876 https://cmsdata.iucn.org/downloads/bangladesh_climate_change_strategy_and_action_plan_2009.pdf.

\section{Figure Caption}




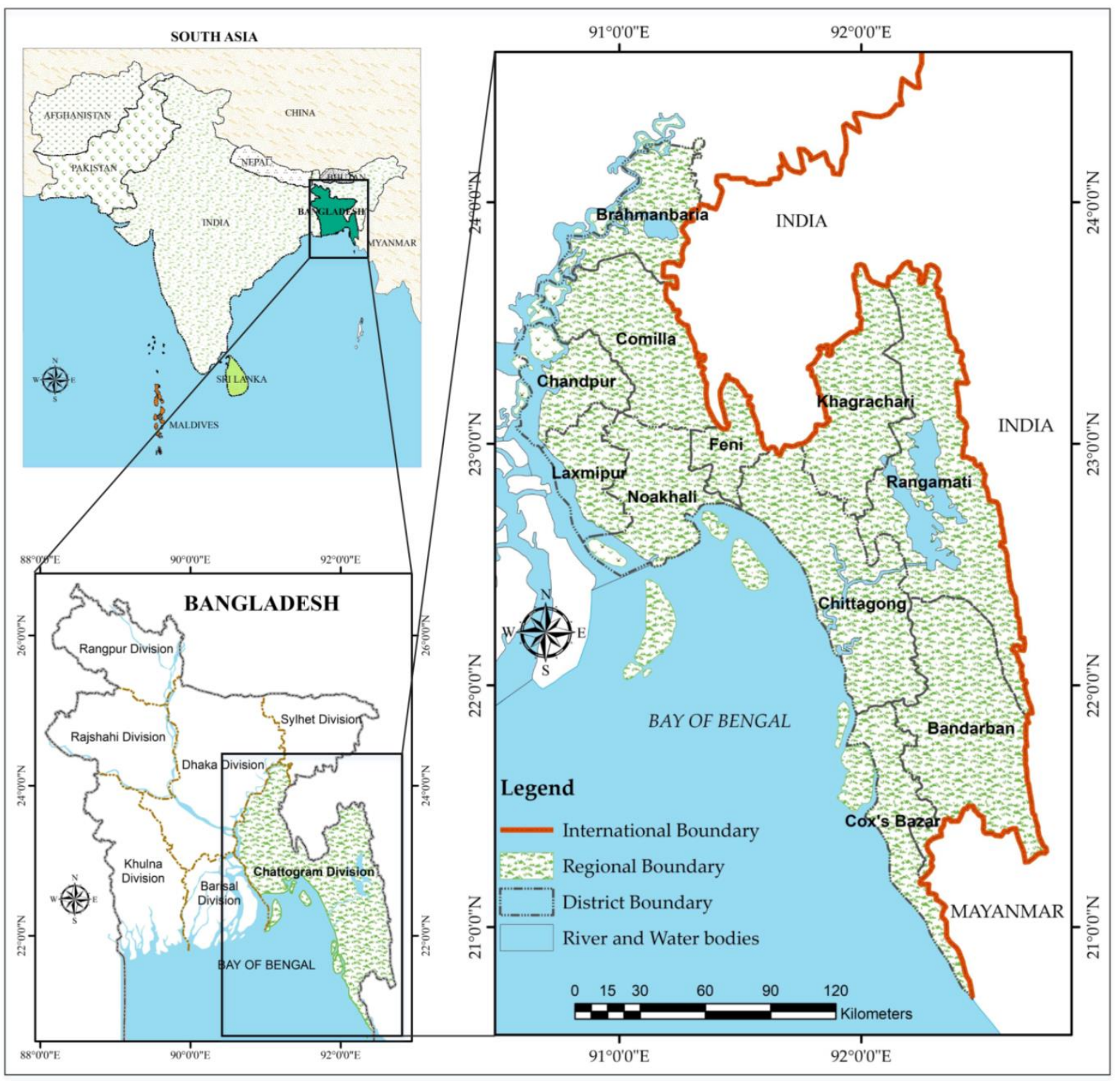

Fig. 1 Location of the study area the Southeastern region of Bangladesh 


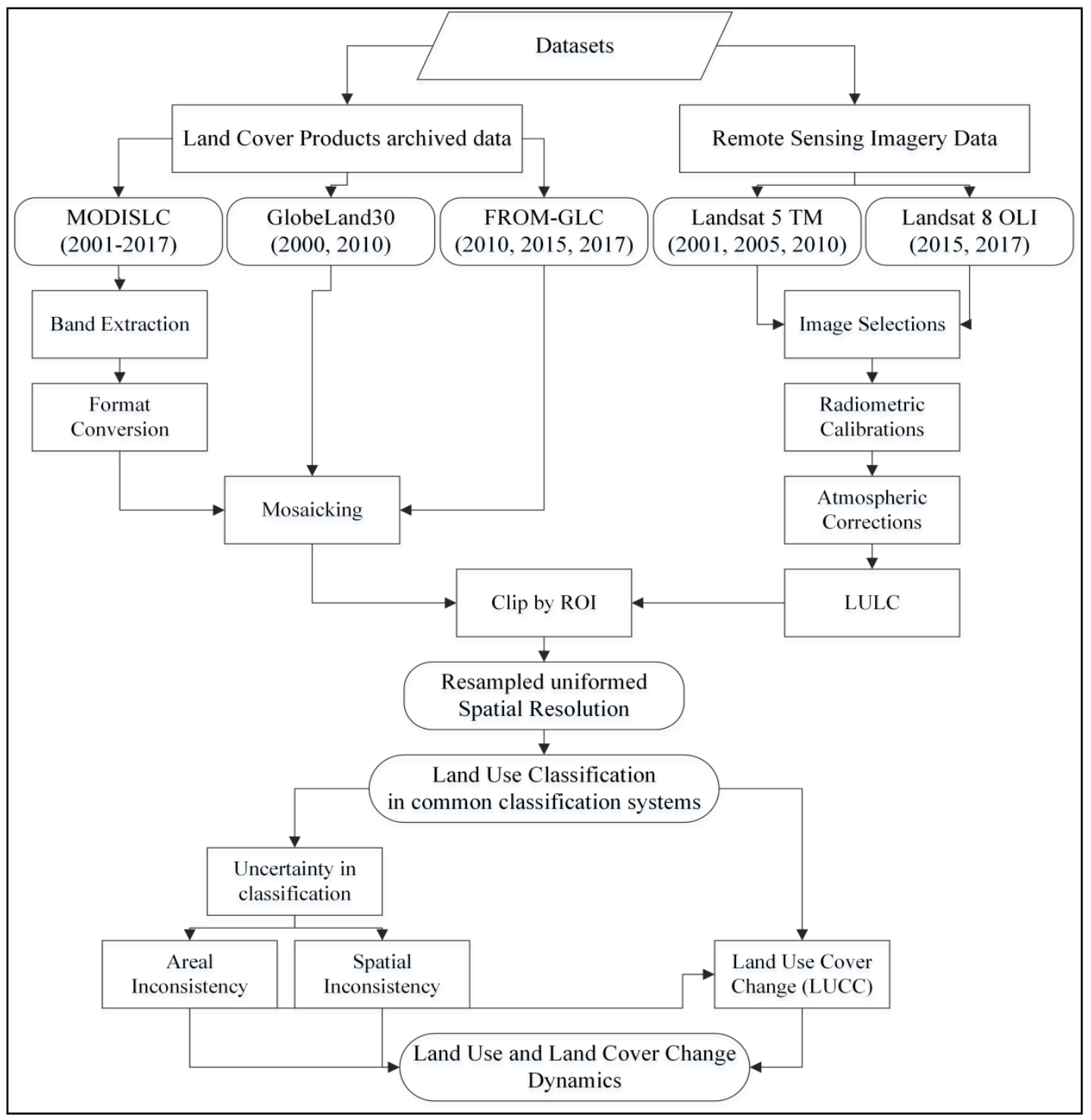

881 Fig. 2 Data analysis flowchart. ROI: Region of Interest; LULC: Land Use and Land Cover; LUCC: Land Use Cover 882 Change. 


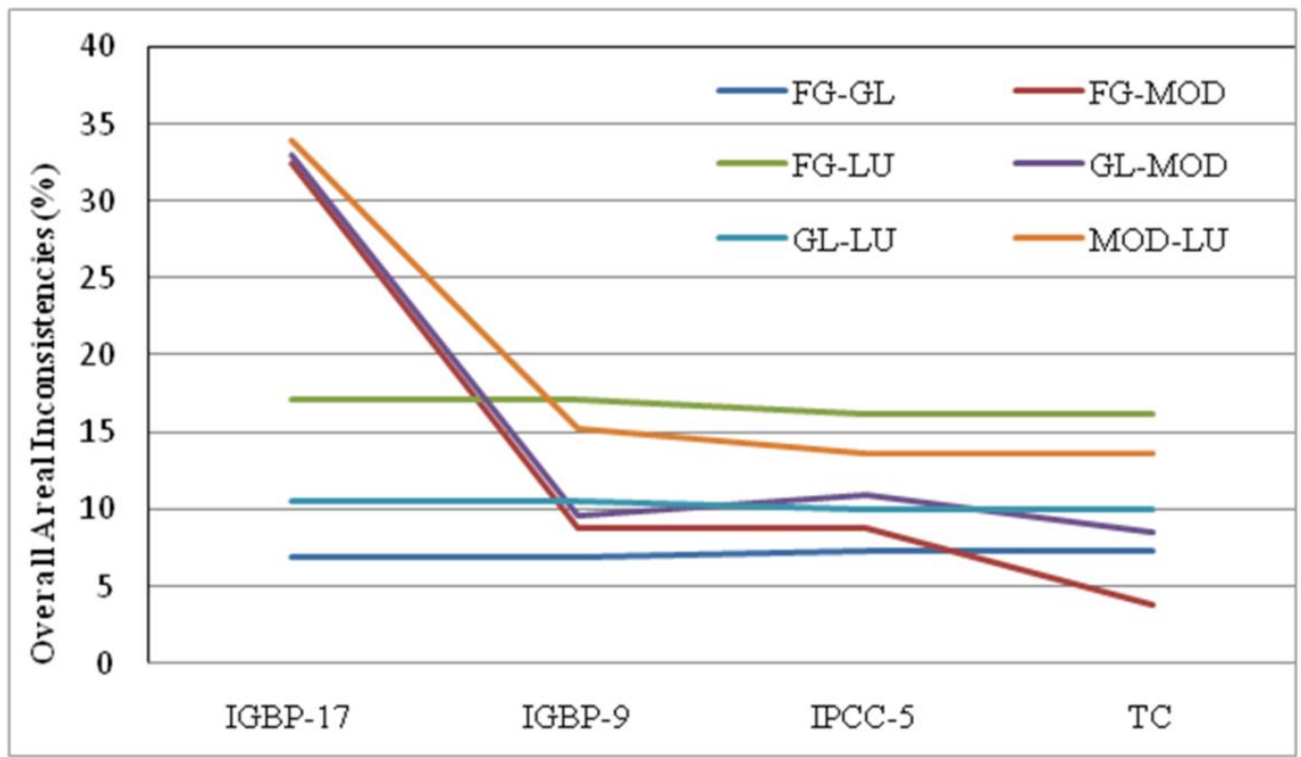

884 Fig. 3 Overall areal inconsistencies between pairwise of the FROM-GLC, GlobeLand30, MODISLC, and LULC class of Landsat TM/ETM+ datasets in four common classification systems (FG: FROM-GLC datasets; GL: GlobeLand30 datasets; MOD: MODISLC datasets; and LU: Land use and land cover classes of Landsat TM/ETM+ datasets). 

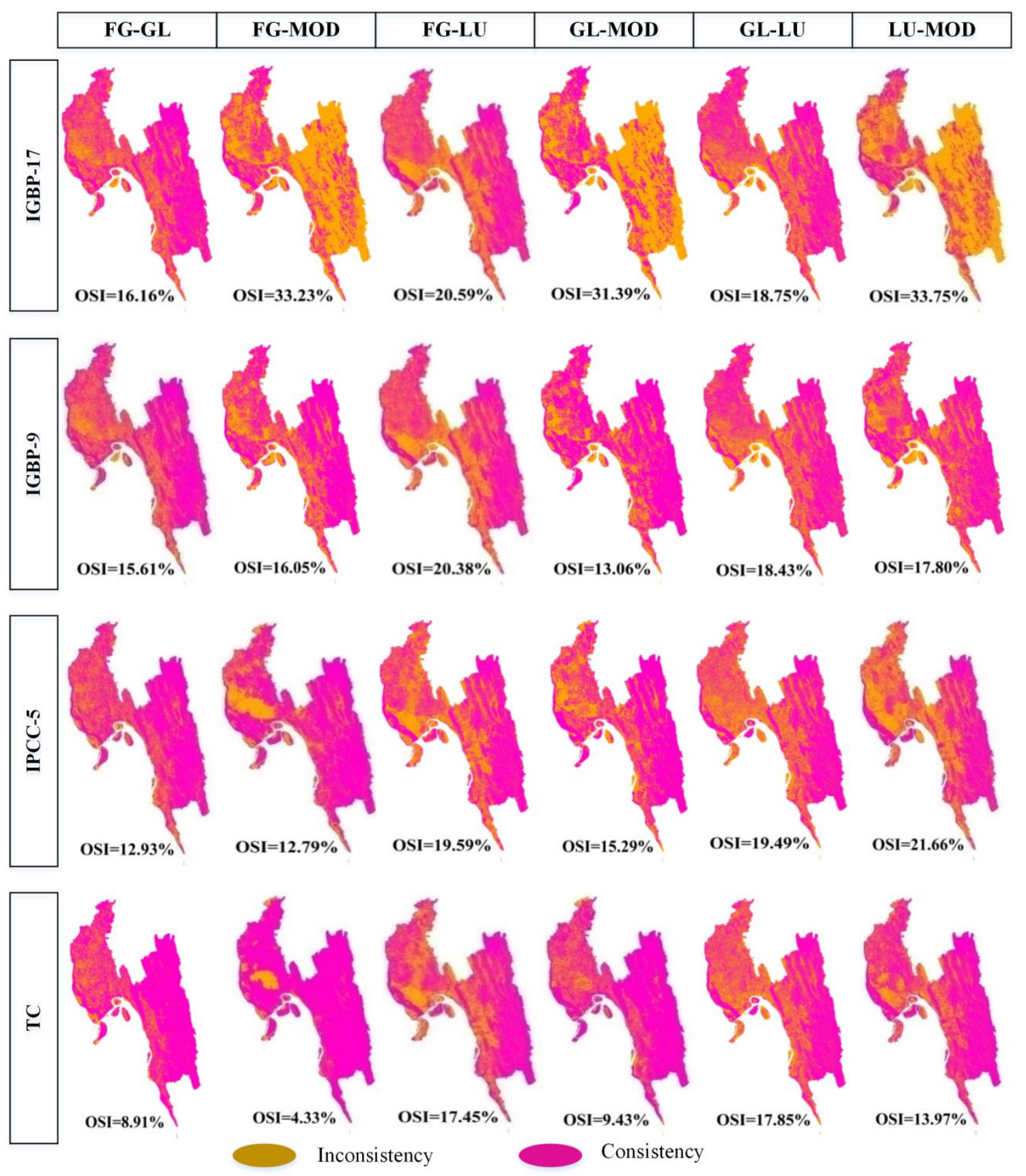

889 Fig.4 Overall spatial inconsistencies (OSI) in the pairwise comparison of FROM-GLC, GlobeLand30, MODISLC, and LULC datasets in the four common classification systems (FG: FROM-GLC datasets; GL: GlobeLand30

891 datasets; MOD: MODISLC datasets; and LU: Land use and land cover classes of remote sensing imaginary datasets) 

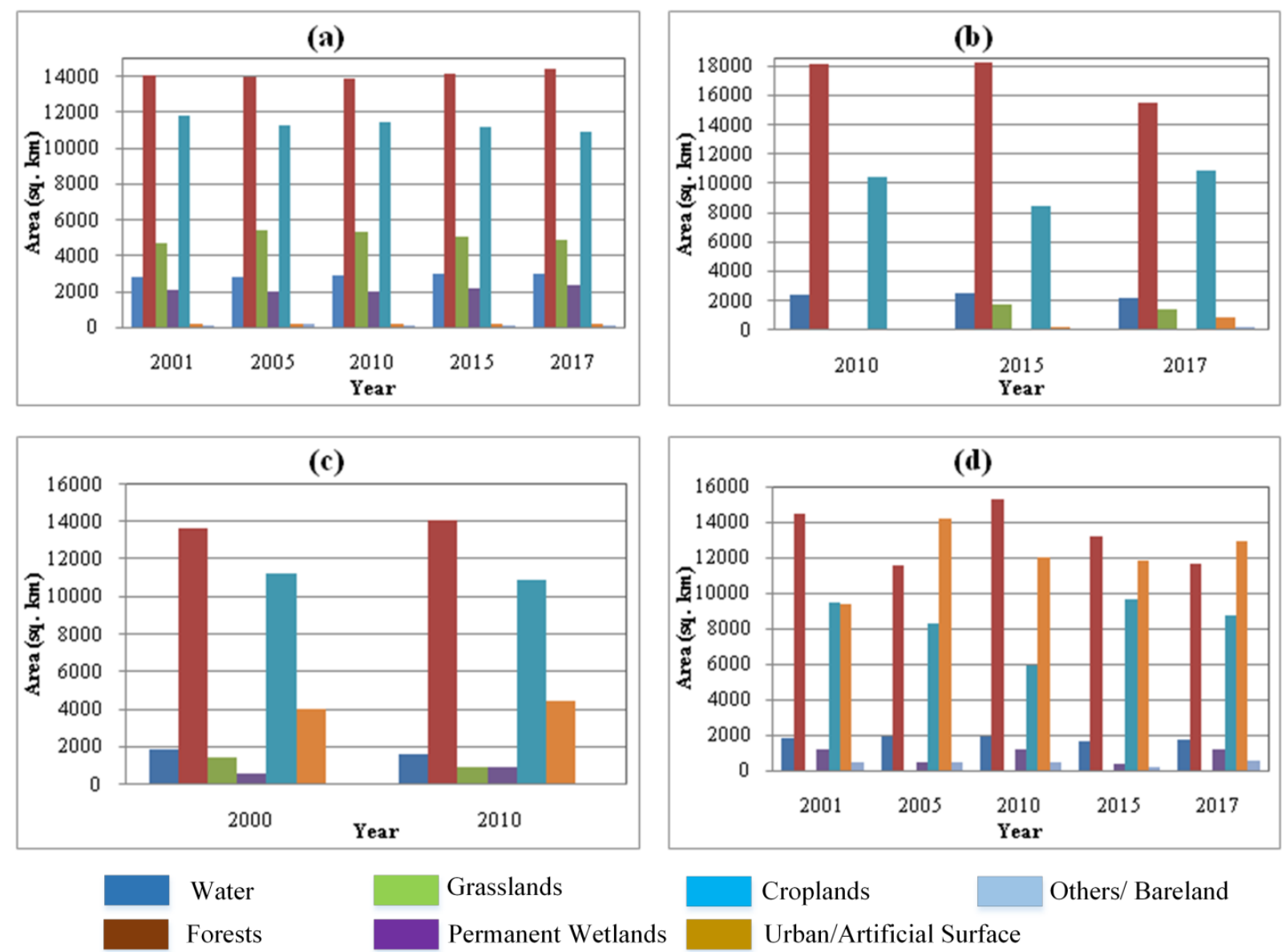

\section{Croplands}

Others/ Bareland

Urban/Artificial Surface

893 Fig. 5 Land use classification of the southeastern region of Bangladesh from (a) MODISLC, (b) FROM-GLC, (c) 

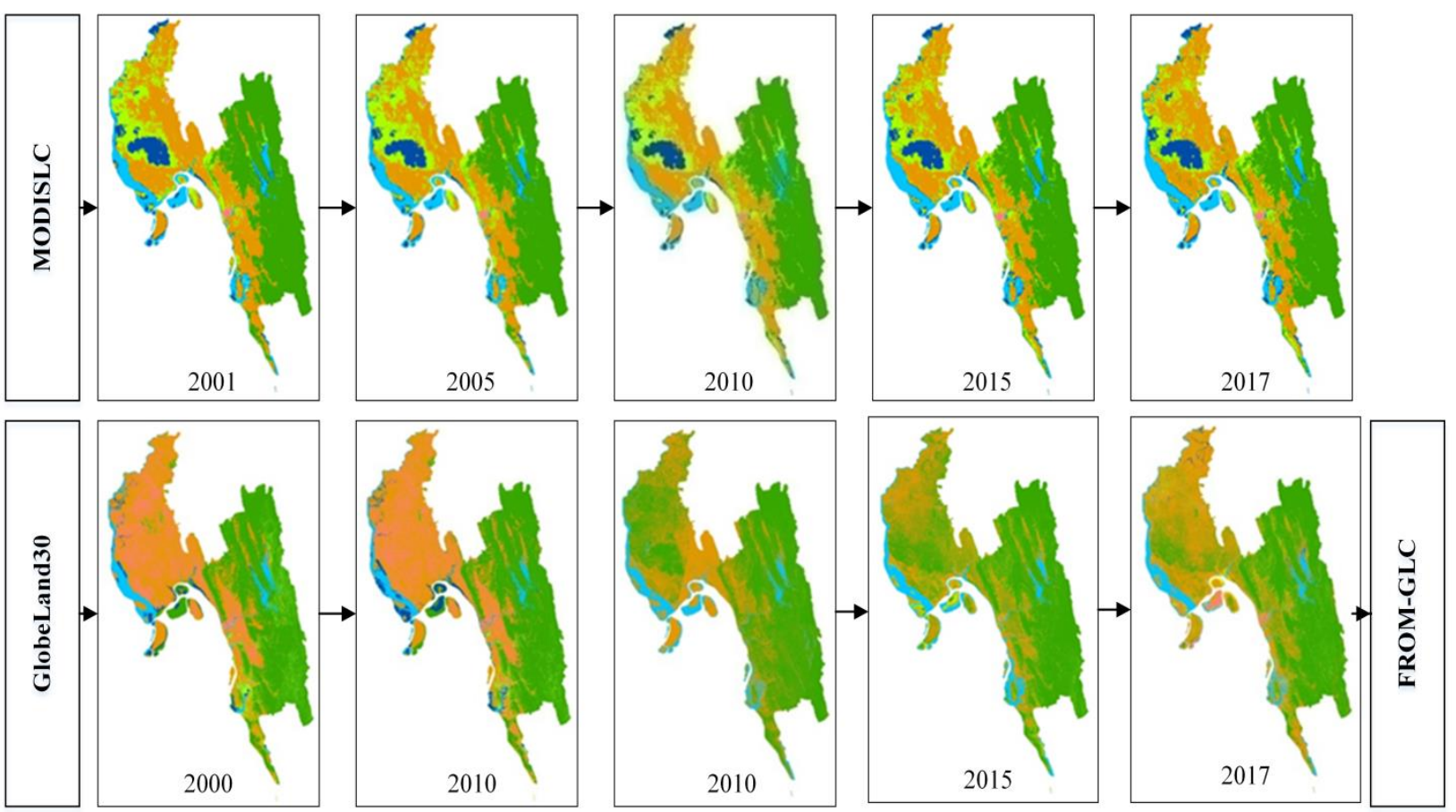

895
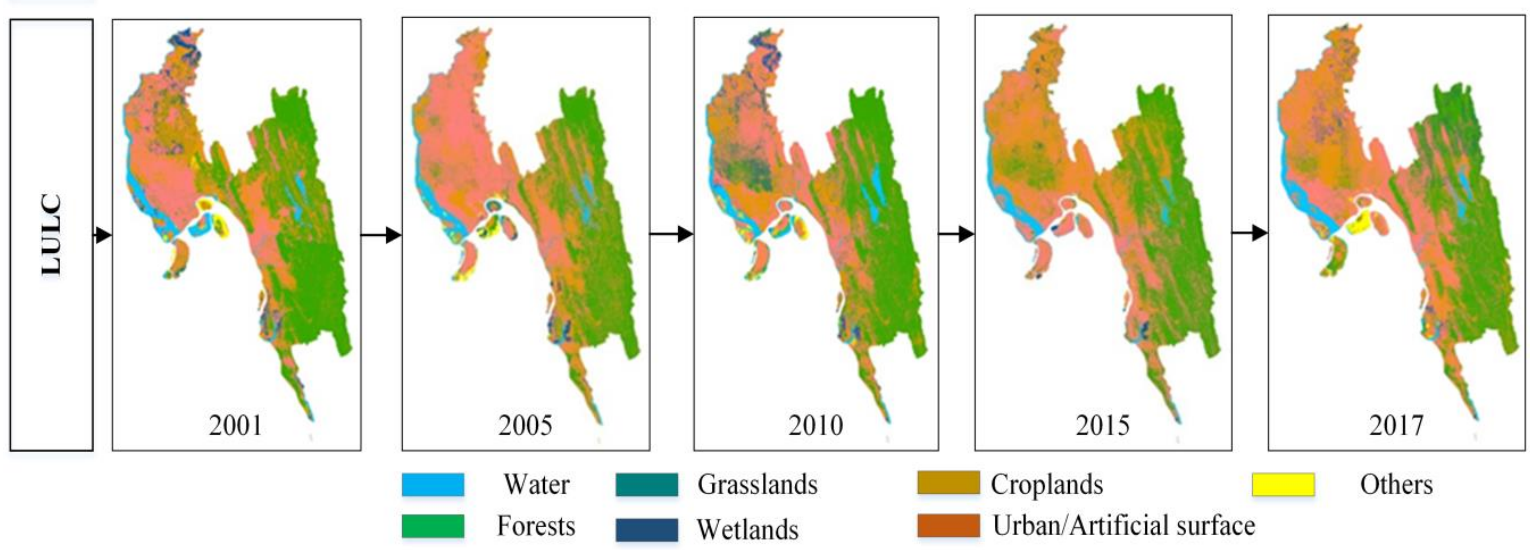

Others

896 897

Fig. 6 Land use classification of the southeastern region of Bangladesh from the MODISLC, GlobeLand30, FROMGLC, and LULC of Landsat imaginary datasets. 

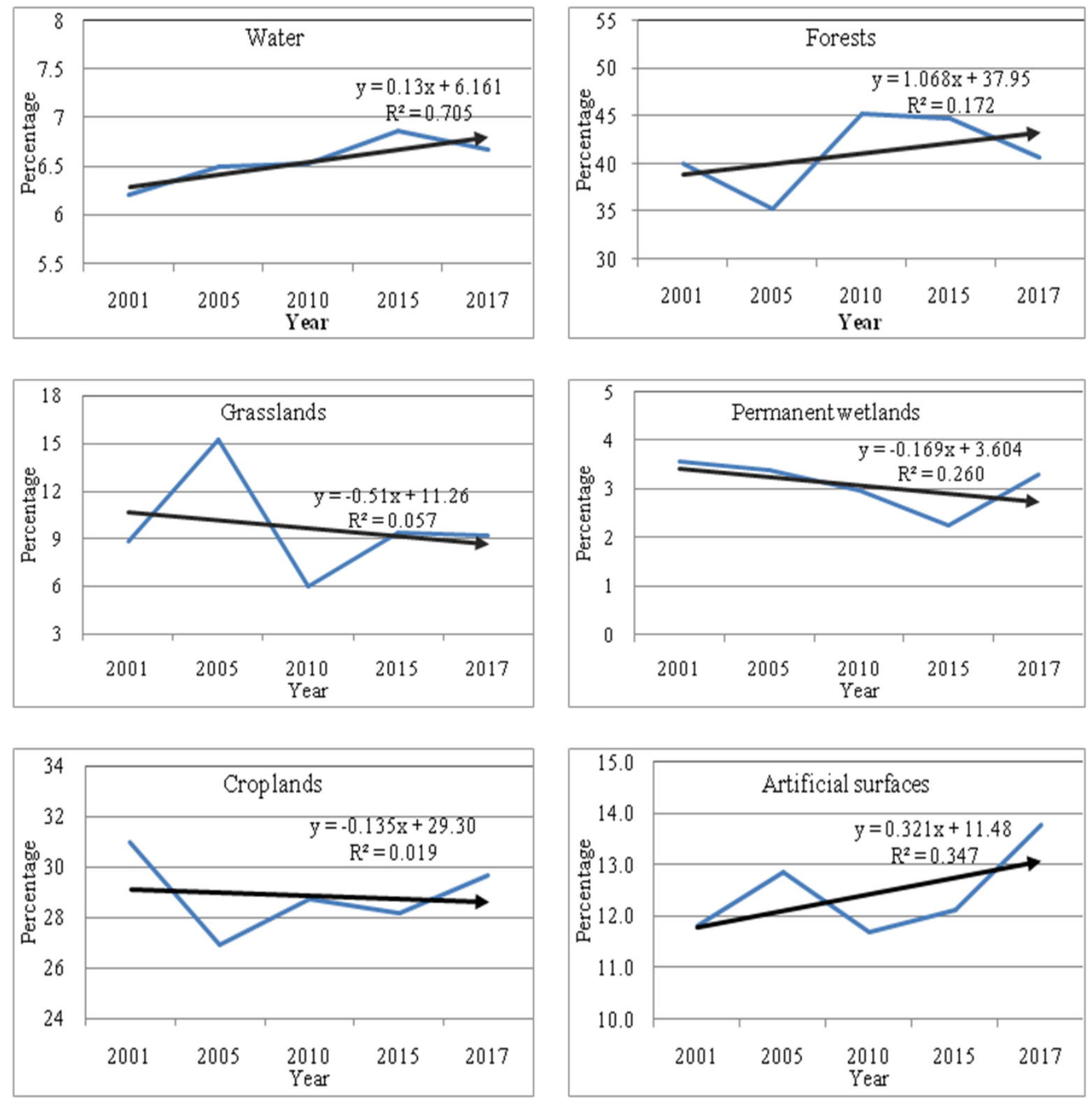

Fig. 7 The different LUCC status at the southeastern region of Bangladesh from different land cover products in average of the MODISLC (2001 to 2017), FROM-GLC (2010, 2015, 2017), GlobeLand30 (2000, 2010), and Landsat imaginary $(2001,2005,2010,2015,2017)$ datasets. 


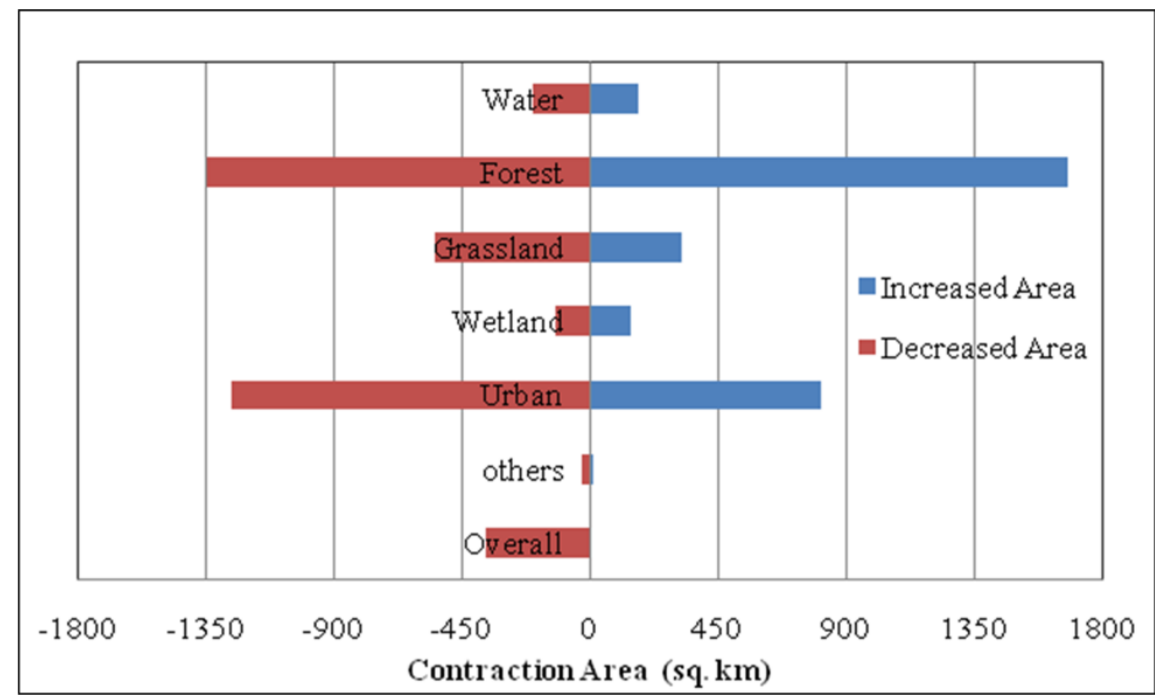

903 Fig. 8 The contraction of croplands area with all other LUCC classes at the southeastern region of Bangladesh from 904 2001 to 2017.

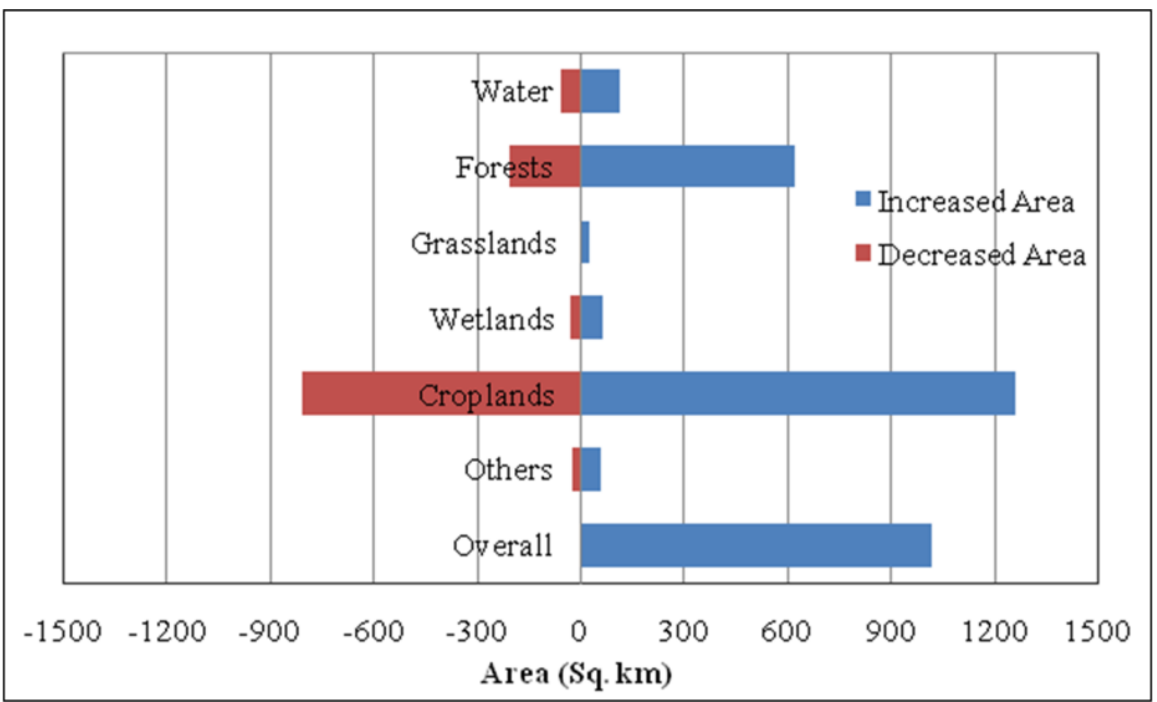

906 Fig. 9 The impacts of urban and built-up areas by major land cover classes of the study area from 2001 to 2017 in 907 combination of four different land cover products 


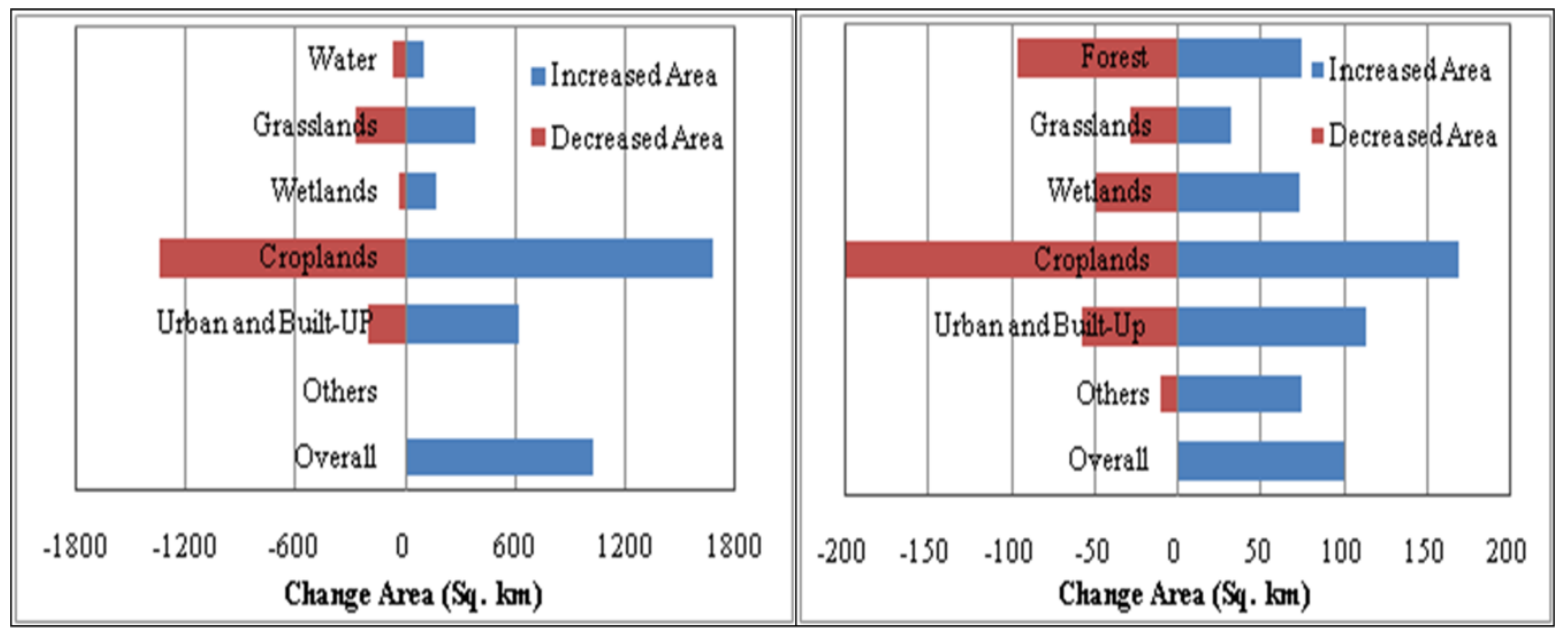

(a)

(b)

909 Fig. 10 The impacts of (a) forest covers and (b) water bodies in major LUCC classes in four different lands cover products from 2001 to 2017. 